\title{
Optimal Monetary Policy and Stock Market Fluctuations
}

\author{
Sahar Bashiri ${ }^{1}$, Mosayeb Pahlavani ${ }^{2}$, Reza Boostani ${ }^{3}$ \\ ${ }^{1}$ Department of Economics, University of Sistan and Baluchestan, Zahedan, Iran. \\ ${ }^{2}$ Department of Economics, University of Sistan and Baluchestan, Zahedan, Iran. \\ ${ }^{3}$ The Central Bank of Iran. \\ Correspondence: Sahar Bashiri, Department of Economics, University of Sistan and Baluchestan, Zahedan, Iran.
}

Received: January 25, 2016

Accepted: February 14, $2016 \quad$ Available online: February 23, 2016

doi:10.11114/aef.v3i2.1402

URL: http://dx.doi.org/10.11114/aef.v3i2.1402

\begin{abstract}
This study investigates the monetary policy rule including money growth and optimal Ramsey policy in restraining the stock market Fluctuations. We apply a new Keynesian monetary framework with nominal wage and price rigidities within a DSGE model for Iranian economy.

Bubbles in our model emerge through a positive feedback loop mechanism supported by self-fulfilling beliefs. The sentiment shock, which represents the size of current bubbles relative to newly born bubbles, causing bubbles movement and it transfers to the real economy through endogenous credit constraint. Moreover, this study investigates the impulse and response between sentiment shock and fluctuation in aggregate variables.

Our empirically findings show that: first, applying Ramsey optimal monetary policy decreases the central bank's loss function, relative to monetary policy rule with money growth. Second, the sentiment shock drives the movements of stock market fluctuations and variations in real economy, leading to explain the positive contemporaneous correlation between stock prices and the real economy and it helps explaining the business cycles in Iran.
\end{abstract}

Keywords: DSGE model, New Keynesian, Optimal Monetary Policy, Stock Market Fluctuations.

\section{Introducation}

In the wake of the recent global financial crisis, evidence shows that asset price bubbles and their collapse typically precede financial crises. There was a strong consensus about the importance of achieving a low and stable inflation rate as the main goal of monetary policy in the last two decades. Accordingly, identifying the monetary policy conduction in a stock market bubble and the appropriate policy responses to these fluctuations and their impacts on macroeconomic variables are important. Therefore, this paper aims to provide a theoretical and empirical study to address this question: How should monetary policy be conducted in stock market bubbles?

In recent years there has been increasing interest in research relating to explore the monetary policy and asset market (see, e.g., Bernanke and Gertler 1999, 2001; Cecchetti et al. 2002; Bernanke 2002; Bernanke and Kuttner 2005; Robinson and Stone 2006; Roubini 2006; Christiano et al. 2008, 2010; Castelnuovo and Nistico 2010; Funke et al. 2010; Gali 2011; Ikeda 2013). The role of monetary policy that should play within bubbles has become the main concern of policy-makers in many countries in last decades. Many authors and policy makers argue on appropriate response to asset prices and financial conditions specially and more broadly during financial crises.

The consensus view among most policy makers in response to these fluctuations before the financial crisis was that central banks should focus on controlling inflation and the output gap, and the growth of financial asset prices should ignore, unless the asset price fluctuations appear as a threat to the stability of inflation and output (see, e.g., Bernanke and Gertler, 1999, 2001; Bernanke, 2002; Kohn, 2006, 2008). Later, that view was fractured, reigniting the debate on achieving stable low inflation for ensuring financial stability is not adequate, and the central bank should pay attention to asset price volatility and its following crisis (see, e.g., Cecchetti et al. 2000; Borio and Lowe, 2002; Leijonhufvud, 2007; Gali, 2011). Therefore, the optimal role of monetary policy to strike a balance between stabilization of the bubble and stabilization of aggregate demand has been the subject of a debate.

For example, Bernanke and Gertler $(1999,2001)$ in two influential papers provide important insights about monetary policy and asset price volatility. Their basic idea is that central banks should view price stability and financial stability 
as highly complementary and mutually consistent objectives. They made the case that monetary policy should respond to asset prices only to the extent that they have implications for future inflation. Gali (2011) examine the impact of alternative monetary policy rules on a rational asset price bubble, through the lens of an overlapping generations model with nominal rigidities. A systematic increase in interest rates in response to a growing bubble is shown to enhance the fluctuations in the latter, through its positive effect on bubble growth. The optimal monetary policy seeks to strike a balance between stabilization of the bubble and stabilization of aggregate demand. His main findings call into question the theoretical foundations of the case for "leaning against the wind" monetary policies. Monetary tightening in an asset price bubble raises the real interest rate that accelerates the bubble growth.

Ikeda (2013) present an estimated monetary DSGE model of asset price bubble and agency costs in firm's price setting decisions. In his model following Miao et.al (2013), bubbles emerge through a positive feedback loop mechanism supported by self-fulfilling beliefs. He also introduces nominal price and wage rigidities in the model. He argues that inflation remains moderate in the boom, because a loosing in financial tightness lowers the agency costs and adds downward pressure on inflation. The optimal monetary policy calls for monetary tightening to restrain the boom at the cost of greater volatility in inflation. Furthermore, he investigates the importance of sentiment shock in explaining the movements of stock market fluctuations and variations in real economy.

This paper investigates the monetary policy rule in restraining the stock market fluctuations with applying dynamic stochastic general equilibrium models under two alternative monetary policy rule, one with money growth and the other with optimal Ramsey policy respectively, since there is not any empirical and theoretical study on assessing the relationship between monetary policy and asset market bubbles for Iranian economy.

In this study, we develop Ikeda's monetary DSGE model with appropriate framework for Iranian economy, and this study contributes to the literature in several aspects compare to Ikeda's. First, this paper sets up a calibrated model which we employ quarterly Iranian data. Second, we consider a small economy with oil export which is subject to oil price shocks frequently. Third, we apply "Money in Utility" approach which looks more plausible to utilize for studying Iranian economy. Fourth, in addition to the TFP shock, the monetary policy shock, the government spending shock, the sentiment shock such as study by Ikeda (2013), we study the oil income shock. Fifth, this paper uses different specifications for balancing government budget, which are financed through lump-sum taxation to households, oil income and issuing money. Sixth, we consider monetary regime including money growth and optimal Ramsey policy under which the Ramsey planner maximizes the representative household's welfare, taking private sector optimizing decisions to study the Iran's central bank behavior. Therefore, this model can help us to analysis the effect of stock market bubbles on macroeconomic variables in economy.

The rest of the paper is structured as follows: Section 2 outlines our model. Section 3 discusses the data and calibrated parameters. Section 4 presents and interprets our main results, and finally, section 5 concludes the paper.

\section{Method}

We consider an infinite-horizon economy that consists of wholesale goods firms, retailers, final goods firms, investment goods firms, households, government and the central bank. Households maximize their utility function subject to a budget constraint, and supply labor to wholesale goods firms. Wholesale goods firms which produces wholesale goods own capital, and they use an identical technology to combine capital and labor in order to produce goods. They are subject to credit constraint because of which a stock price bubble emerges. Retailers are acting in monopolistically competitive markets, and transforming one unit of wholesale goods into one unit of retail goods. Retailers face nominal price rigidities. Final goods firms purchase the retail goods and combine them to produce final goods. Investment goods firms produce investment or capital goods subject to adjustment costs. Wholesale goods firms purchase capital goods from investment goods producers. Model setup is based on new Keynesian framework with nominal rigidity in both wages and prices. The government in this economy spends resources on consumption of the final goods, and the central bank conducts monetary policies in the economy. The Ramsey planner maximizes the representative household's welfare. International trade depends on oil market and it is one of the sources of financing the government budget. Model is inspired by Miao et al. (2013) and Ikeda (2013), and it can help us to analysis the effect of stock market bubbles on macroeconomic variables in economy.

\subsection{Households}

There is a continuum of identical households placed on unit interval with measure unity, $j \in[0,1]$. Each household obtains utility from consumption, leisure and holding money balances according to the following discounted utility function, 


$$
E_{t} \sum_{s=0}^{\infty} \beta^{s}\left\{\log \left(C_{t+s}-h C_{t+s-1}\right)-\psi_{L} \frac{L_{t+s, j}^{1+v}}{1+v}+\frac{v}{1-\sigma_{q}}\left(\frac{M_{t+s}^{d}}{P_{t+s}}\right)^{1-\sigma_{q}}\right\}, \quad 0<\beta<1
$$

where $\beta$ is the subjective discount factor, $E_{t}$ is the expectation operator, $h$ is habit persistence in preferences, whereas $v$ and $\psi_{L}$ are weights associated with utility from money holdings and leisure, respectively. Moreover, $C_{t}$ indicates consumption, $L_{t}$ indicates labor, $M_{t}$ indicate the nominal money balances, and $P_{t}$ indicates the price of final goods.

This representative household maximizes his utility function subject to a budget constraint,

$$
P_{t} C_{t}+M_{t}^{d}-M_{t-1}^{d}+S_{t} e_{t+1}+D_{t} \leq W_{t, j} L_{t, j}+\left(\pi_{t}^{s}+S_{t}\right) e_{t}+R_{t-1} D_{t-1}+\pi_{t}^{p}+T_{t}
$$

here $W_{t}$ is nominal wage, $D_{t}$ is nominal bonds, $e_{t+1}$ is stock holdings, $R_{t}$ is nominal interest rate, $S_{t}$ is average stock price, $\pi_{t}^{s}$ is average dividends, $\pi_{t}^{p}$ is profit of producers, $T_{t}$ is lump-sum Taxes.

The household's consumption-saving problem is formulated as follows. The first order conditions with respect to $C_{t}$, $M_{t}^{d}$ and $D_{t}$ are,

$$
\begin{gathered}
P_{t} \Lambda_{t}=\left(\frac{1}{C_{t}-h C_{t-1}}-\beta h E_{t} \frac{1}{C_{t+1}-h C_{t}}\right) \\
\Lambda_{t}-E_{t} \beta \Lambda_{t+1}=v\left(\frac{M_{t}^{d}}{P_{t}}\right)^{-\sigma_{q}} \frac{1}{P_{t}} \\
1=E_{t}\left(\beta \frac{\Lambda_{t+1}}{\Lambda_{t}} R_{t}\right)
\end{gathered}
$$

where $\Lambda_{t}$ is the Lagrange multiplier on the budget constraint in period $t$. Using equation (5), demand for real money balances could derive from equation (4),

$$
1-\frac{1}{R_{t}}=v\left(\frac{M_{t}^{d}}{P_{t}}\right)^{-\sigma_{q}} \frac{1}{\Lambda_{t} P_{t}}
$$

where, the real demand of money is a function of interest rate, price level and consumption. In equilibrium, demand and supply of money are equal; therefore, money market equilibrium determines the interest rate.

Following Christiano et al. (2005) and Ikeda (2013), a household can optimize its wage rate with probability $1-\xi_{w}$ in each period. With probability $\xi_{w}$, the household cannot optimize its wage; in this case it sets its wage rate $W_{t}(j)$ as follows,

$$
W_{t+s}(j)=\left\{\begin{array}{ccc}
\overline{W_{t}}(j) & \text { if } & s=0 \\
{\left[\prod_{k=1}^{s}\left(\pi_{t+k-1} z_{t+k-1}\right)^{l w}(\pi z)^{1-l w}\right] \bar{W}(j)} & \text { if } & s=1,2, \ldots
\end{array}\right.
$$

where $\pi_{t}$ denotes the gross rate of inflation, $\pi$ denotes steady state inflation and $l w$ is the wage indexation to product past inflation and the past growth rate of TFP. If household $j^{\text {th }}$ had reset the wage in period $t$ and kept it constant until $t+s$, the wage could be expressed as $W_{t+s}(j)=W_{t}(j) \Pi_{t, t+s}^{w}$.

The wage-setting problem can be expressed from maximizing the household utility (1) subject to demand curve for labor,

$$
L_{t+s}(j)=\left(\frac{W_{t+s}(j)}{W_{t+s}}\right)^{\frac{\lambda_{w}}{1-\lambda_{w}}} L_{t+s}
$$

The wage-setting equation is as follows (see the Appendix A.1-A.2 for derivation): 


$$
0=E_{t} \sum_{s=0}^{\infty}\left(\beta \xi_{w}\right)^{s} \hat{\lambda}_{t+s} \frac{L_{t+s}(j)}{1-\lambda_{w}}\left\{\bar{w}_{t} \hat{w}_{t} \bar{\Pi}_{t, t+s}^{w}-\psi_{L} \lambda_{w} \frac{L_{t+s}(j)^{v}}{\hat{\lambda}_{t+s}}\right\}
$$

Real effective wage is define as $\hat{w}_{t}=W_{t} / P_{t} A_{t}$, and relative wage is define as $\bar{w}_{t}=\bar{W}_{t} / W_{t}$, which is the ratio of optimized wage to aggregate wage level (which includes both optimizers and non-optimizers), and $\lambda_{t}=P_{t} A_{t} \Lambda_{t}$. In the Calvo setup, because optimizers (and hence non-optimizers) are randomly chosen from the population, the average wage of non-optimizers in $t-1$ (which must keep their wage constant) is equal to the overall wage index in $t-1$ no matter when they optimized for the last time. Hence, $W_{t}(j)$ depends only on aggregate states, and $j$ is omitted hereafter. According to Appendix A.3 dividing through by $W_{t-1}$ and rearranging yields the relative wage of optimizers as an increasing function of the inflation rate,

$$
\bar{w}_{t}=\left(\left[1-\xi_{w}\left(\frac{\hat{w}_{t-1}}{\hat{w}_{t}} \frac{\Pi_{t-1, t}^{w}}{\pi_{t} z_{t}}\right)^{\frac{1}{1-\lambda_{w}}}\right]\left(1-\xi_{w}\right)^{-1}\right)^{1-\lambda_{w}}
$$

Following the household wage-setting maximization problem in equation (9), we can transform the wage setting condition as follows.

$$
\begin{aligned}
& F_{w, t}=E_{t} \sum_{s=0}^{\infty}\left(\beta \xi_{w}\right)^{s} \frac{\hat{\lambda}_{t+s}}{1-\lambda_{w}}\left(\frac{\hat{w}_{t}}{\hat{w}_{t+s}}\right)^{\frac{\lambda_{w}}{1-\lambda_{w}}}\left(\bar{\Pi}_{t, t+s}^{w}\right)^{\frac{1}{1-\lambda_{w}}} L_{t+s} \\
& K_{w, t}=E_{t} \sum_{s=0}^{\infty}\left(\beta \xi_{p}\right)^{s} \psi_{L} \frac{\lambda_{w}}{1-\lambda_{w}}\left(\frac{\hat{w}_{t}}{\hat{w}_{t+s}}\right)^{\frac{\lambda_{w}(1+v)}{1-\lambda_{w}}}\left(\bar{\Pi}_{t, t+s}^{w}\right)^{\lambda_{w}(1+v)} L_{t+s}^{1-\lambda_{w}} L_{t+v)}^{(1+v)} \\
& \bar{w}_{t}=\left(\frac{1}{\hat{w}_{t}} \frac{K_{p, t}}{F_{p, t}}\right)^{\frac{1-\lambda_{w}}{1-(1+v) \lambda_{w}}}
\end{aligned}
$$

\subsection{Wholesale good Firms}

There is a continuum of wholesale good firms, indexed by $j$. Firms which produce wholesale goods own capital, and they use an identical technology to combine capital $K_{t}^{j}$ and labor $L_{t}^{j}$ to produce goods $Y_{t}^{j}$ with the following production function,

$$
Y_{t}^{j}=\left(K_{t}^{j}\right)^{\alpha}\left(A_{t} L_{t}^{j}\right)^{1-\alpha}, \quad 0<\alpha<1, \quad z_{t} \equiv A_{t} / A_{t-1}
$$

where $z_{t}$ is the growth rate of total factor productivity (TFP) following an $A R(1)$ process,

$$
\log \left(z_{t} / z\right)=\rho_{z} \log \left(z_{t-1} / z\right)+\varepsilon_{z, t}, \quad 0 \leq \rho_{z}<1
$$

with $\varepsilon_{z, t} \sim N\left(0, \sigma_{z}^{2}\right)$. The firm's capital stock evolves according to:

$$
K_{t+1}^{j}=(1-\delta) K_{t}^{j}+\varepsilon_{t}^{j} I_{t}^{j}, \quad 0<\delta<1
$$

where $I_{t}^{j}, \delta, \varepsilon_{t}^{j}$ denote respectively investment, the capital depreciation rate, the idiosyncratic shock to investment. The $\varepsilon_{t}^{j}$ is iid across firms and over time and follows the Pareto distribution $\Phi$ as follows,

$$
\begin{gathered}
\Phi:[1, \infty) \longrightarrow[0,1] \\
\Phi(\varepsilon)=1-\varepsilon^{-\eta}, \quad \eta>0
\end{gathered}
$$

In order to formulate the financial friction in capital market, it is assumed that the wholesale good firms have to finance the cost of investment and working capital at the beginning of production process. Let $V_{t}^{j}\left(K_{t}^{j}\right)$ represents the stock 
market value of the firm with assets $K_{t}^{j}$ at time $t$. The wholesale good firm $j^{\text {th }}$ faces a borrowing constraint, given by,

$$
P_{t}^{I} I_{t}^{j}+W_{t} L_{t}^{j} \leq\left(1-\delta_{e}\right) E_{t} \frac{\beta \Lambda_{t+1}}{\Lambda_{t}} \bar{V}_{t+1}^{j}\left(\kappa K_{t}^{j}\right)
$$

where $\delta_{e}$ is the probability by which a firm may exit the market and has no value. Similar to Miao et al. (2013), firm $j$ pledges a fraction $\kappa \in(0,1)$ of capital stock $K_{t}^{j}$ as the collateral at the beginning of period $t$. Therefore, the parameter $\kappa$ reflects the friction of collateral in the credit market and represents the degree of financial market imperfections. The stock market value of the collateral is equal to $E_{t}\left(\beta \Lambda_{t+1} / \Lambda_{t}\right) \bar{V}_{t+1}^{j}\left(\kappa K_{t}^{j}\right)$ at the end of period $t$. The lender never allows the loan repayment to exceed this value. If firm $j$ loan above $P_{t}^{I} I_{t}^{j}+W_{t} L_{t}^{j}$, it may walk away and leave the collateralized assets $\kappa K_{t}^{j}$ behind. In this case, the lender runs the firm with the collateralized assets $\kappa K_{t}^{j}$ at the beginning of period $t+1$ and obtains the smaller firm value $E_{t}\left(\beta \Lambda_{t+1} / \Lambda_{t}\right) \bar{V}_{t+1}^{j}\left(\kappa K_{t}^{j}\right)$ at the end of period $t$.

As the investment is irreversible at firm level, the firm's value satisfies the following Bellman equation with maximizing its value, subject to (14), (16) and (18):

$$
V_{t}^{j}\left(K_{t}^{j}\right)=\max _{\left\{I_{t}^{j} \geq 0, L_{t}^{j} \geq 0\right\}} P_{t}^{w} Y_{t}^{j}-\left(W_{t} L_{t}^{j}+P_{t}^{I} I_{t}^{j}\right)+\left(1-\delta_{e}\right) E_{t} \frac{\beta \Lambda_{t+1}}{\Lambda_{t}} V_{t+1}^{j}\left(K_{t+1}^{j}\right)
$$

The first-order condition with respect to $L_{t}^{j}$ yields the following equations,

$$
\begin{gathered}
P_{t}^{w}=\frac{W_{t}\left(1+\xi_{t}^{j}\right)}{(1-\alpha) Y_{t}^{j} / L_{t}^{j}}=\frac{W_{t}\left(1+\xi_{t}^{j}\right)}{(1-\alpha)\left(K_{t}^{j}\right)^{\alpha} A_{t}^{1-\alpha}\left(L_{t}^{j}\right)^{-\alpha}} \\
L_{t}^{j}=\left[\frac{P_{t}^{w}(1-\alpha) A_{t}^{1-\alpha}}{W_{t}\left(1+\xi_{t}^{j}\right)}\right]^{\frac{1}{\alpha}} K_{t}^{j}
\end{gathered}
$$

where $\xi_{t}^{j}$ is the Lagrange multiplier on the credit constraint. After solving the labor choice problem, we obtain the operating profits:

$$
R_{t}^{j} K_{t}^{j}=\left[P_{t}^{w}\left(K_{t}^{j}\right)^{\alpha}\left(A_{t} L_{t}^{j}\right)^{1-\alpha}-W_{t} L_{t}^{j}\right]=\frac{\alpha+\xi_{t}^{j}}{1+\xi_{t}^{j}}\left[\frac{(1-\alpha) A_{t}}{\left(1+\xi_{t}^{j}\right) W_{t}}\right]^{\frac{1-\alpha}{\alpha}}\left(P_{t}^{w}\right)^{\frac{1}{\alpha}} K_{t}^{j}
$$

Substituting the above expression into problem (19) the wholesale firm problem maximizing yields,

$$
V_{t}^{j}\left(K_{t}^{j}\right)=\max _{\left\{I_{t}^{j} \geq 0\right\}} R_{t}^{j} K_{t}^{j}-P_{t}^{I} I_{t}^{j}+\left(1-\delta_{e}\right) E_{t} \frac{\beta \Lambda_{t+1}}{\Lambda_{t}} V_{t+1}^{j}\left(K_{t+1}^{j}\right)
$$

subject to,

$$
P_{t}^{I} I_{t}^{j}+\frac{1-\alpha}{\alpha+\xi_{t}^{j}} R_{t}^{j} K_{t}^{j} \leq\left(1-\delta_{e}\right) E_{t} \frac{\beta \Lambda_{t+1}}{\Lambda_{t}} V_{t+1}^{j}\left(\kappa K_{t}^{j}\right)
$$

Following Miao et al. (2013) and Ikeda (2013), the value of firm is conjectured to take the following form:

$$
V_{t}^{j}\left(K_{t}^{j}\right)=Q_{t}^{j} K_{t}^{j}+B_{t, \tau}^{j}
$$

where $Q_{t}^{j}$ and $B_{t, \tau}^{j}$ are defined in equation (26) and (27), represent the shadow price of capital, or marginal Q and the bubble component of the asset value, respectively.

Miao and Wang (2011b) defined the credit easing effect, firm $j$ can use the bubble $B_{t, \tau}^{j}$ to raise the collateral value and relax the collateral constraint. In this way, firm $\mathrm{j}$ can make more investment and raise the market value of its assets. If lenders believe that firm $j$ 's assets have a high value possibly because of the existence of bubbles and if lenders 
decide to lend more to firm $j$; then firm $j$ can borrow and invest more, thereby making its assets indeed more valuable. This process is self-fulfilling and a bubble may sustain.

$$
\begin{aligned}
Q_{t} & =\left(1-\delta_{e}\right) E_{t} \frac{\beta \Lambda_{t+1}}{\Lambda_{t}} Q_{t+1}^{j} \\
\bar{B}_{t, \tau}^{j} & =\left(1-\delta_{e}\right) E_{t} \frac{\beta \Lambda_{t+1}}{\Lambda_{t}} B_{t+1, \tau+1}^{j}
\end{aligned}
$$

Using (23), (25), (26), (27) and capital stock (16), problem (19) can be written as (see the Appendix A.4 for derivation):

$$
Q_{t}^{j} K_{t}^{j}+B_{t, \tau}^{j}=\max _{\left\{I_{t}^{j} \geq 0\right\}} R_{t}^{j} K_{t}^{j}+\left(Q_{t} \varepsilon_{t}^{j}-P_{t}^{I}\right) I_{t}^{j}+Q_{t}(1-\delta) K_{t}^{j}+\bar{B}_{t, \tau}^{j}
$$

By maximizing problem (28) subject to credit constraint (24) and definition of value of firm (25), the investment defines as follows:

$$
P_{t}^{I} I_{t}^{j}=\left\{\begin{array}{ccc}
Q_{t}\left(\kappa K_{t}^{j}\right)+\bar{B}_{t, \tau}^{j}-\frac{1-\alpha}{\alpha+\xi_{t}^{j}} R_{t}^{j} K_{t}^{j} & \text { if } \varepsilon_{t}^{j} \geq \varepsilon^{*} \\
0 & \text { if } \varepsilon_{t}^{j}<\varepsilon^{*}
\end{array}\right.
$$

Following Miao et al. (2013), the cost of one unit of investment is the purchasing price $P_{t}^{I}$. The benefit how that is the marginal $Q_{t}$. Because of lineality in $I_{t}^{j}$, it is straightforward that the constraint is binding and the investment is maximized when $Q_{t} \geq P_{t}^{I}$, and the investment is zero otherwise.

The investment threshold is $\varepsilon_{t}^{*}=P_{t}^{I} / Q_{t}$. Following Ikeda (2013), only firms with idiosyncratic productivity above threshold $\varepsilon_{t}^{*}$ raise funds up to their credit limit and make investments. Other firms with productivity blew $\varepsilon_{t}^{*}$ do not invest at all.

Following Ikeda (2013), the FOC with respect to $I_{t}^{j}$ yields the Lagrangean as: (see the Appendix A.5 for derivation). Equation (29) reflects that only firms with $\varepsilon_{t}^{j}>\varepsilon_{t}^{*}$ make investment.

$$
\varepsilon_{t}^{*}=P_{t}^{I} / Q_{t}, \xi_{t}^{j}=\frac{\varepsilon_{t}^{j}}{\varepsilon_{t}^{*}}-1 \geq 0
$$

Substituting the investment rule (29) into problem (28) gives,

$$
Q_{t}^{j} K_{t}^{j}+B_{t, \tau}^{j}=R_{t}^{j} K_{t}^{j}+Q_{t}(1-\delta) K_{t}^{j}+\bar{B}_{t, \tau}^{j}+\max \left(\frac{\varepsilon_{t}^{j}}{\varepsilon_{t}^{*}}-1,0\right)\left[Q_{t}\left(\kappa K_{t}^{j}\right)+\bar{B}_{t, \tau}^{j}-\frac{1-\alpha}{\alpha+\xi_{t}^{j}} R_{t}^{j} K_{t}^{j}\right]
$$

Matching coefficients yields:

$$
\begin{aligned}
& Q_{t}^{j}=\left\{\begin{array}{c}
R_{t}^{j}+Q_{t}(1-\delta)+\left(\frac{\varepsilon_{t}^{j}}{\varepsilon_{t}^{*}}-1\right)\left[Q_{t} \kappa-\frac{1-\alpha}{\alpha+\xi_{t}^{j}} R_{t}^{j}\right] \begin{array}{cc}
\text { if } & \varepsilon_{t}^{j} \geq \varepsilon^{*} \\
\text { if } & \varepsilon_{t}^{j}<\varepsilon^{*}
\end{array} \\
R_{t}^{j}+Q_{t}(1-\delta)
\end{array}\right. \\
& B_{t, \tau}^{j}=\left\{\begin{array}{ccc}
\bar{B}_{t, \tau}^{j}+\left(\frac{\varepsilon_{t}^{j}}{\varepsilon_{t}^{*}}-1\right) \bar{B}_{t, \tau}^{j} & \text { if } & \varepsilon_{t}^{j} \geq \varepsilon^{*} \\
\bar{B}_{t, \tau}^{j} & \text { if } & \varepsilon_{t}^{j}<\varepsilon^{*}
\end{array}\right.
\end{aligned}
$$

where, 


$$
G_{t}=\int_{\varepsilon \geq \varepsilon_{t+1}^{*}}\left(\frac{\varepsilon}{\varepsilon_{t}^{*}}-1\right) d \phi(\varepsilon)
$$

Substituting $Q_{t}^{j}$ and $B_{t, \tau}^{j}$ from equations (32) and (33) in equation (26) and (27) yield:

$$
\begin{gathered}
Q_{t}=\left(1-\delta_{e}\right) E_{t} \frac{\beta \Lambda_{t+1}}{\Lambda_{t}}\left[R_{t+1}^{j}+Q_{t+1}(1-\delta)+\int_{\varepsilon \geq \varepsilon_{t+1}^{*}}\left(\frac{\varepsilon}{\varepsilon_{t+1}^{*}}-1\right)\left[Q_{t+1} \kappa-\frac{1-\alpha}{\alpha+\xi_{t+1}^{j}} R_{t+1}^{j}\right] d \phi(\varepsilon)\right] \\
\bar{B}_{t, \tau}^{j}=\left(1-\delta_{e}\right) E_{t} \frac{\beta \Lambda_{t+1}}{\Lambda_{t}} \bar{B}_{t+1, \tau+1}^{j}\left(1+G_{t+1}\right)
\end{gathered}
$$

Equation (35) is the discounted marginal value of capital. The dividends from capital consist of the net return $R_{t+1}^{j}$, the value of depreciated capital $Q_{t+1}(1-\delta)$ and the investment benefit $\left[Q_{t+1} \kappa-\frac{1-\alpha}{\alpha+\xi_{t+1}^{j}} R_{t+1}^{j}\right] G_{t+1}$ of an additional unit increase in capital.

Equation (36) determines the bubble. The bubble generates dividends and it increases the borrowing capacity. This allows the firm to make more investment, generating additional dividends for the idiosyncratic shock, $\varepsilon_{t+1}^{j}$ at time $t+1$.

\subsection{Retailers}

There is a continuum of firms indexed by $i$, on the interval $(0,1)$. They purchase wholesale good at price $P_{t}^{w}$ and transform one unit of wholesale good into one unit of specialized retail good, $Y_{t}(i)$.

\subsection{Final Goods Firms}

There is a chain of final good producers, operating under perfect competition. The firm produces the final good $Y_{t}$ by continuum combining retail goods, using the CES technology:

$$
Y_{t}=\left[\int_{0}^{1} Y_{t}(i)^{\frac{1}{\lambda_{p}}} d i\right]^{\lambda_{p}} \quad \lambda_{p, t}>1
$$

where $\lambda_{p} / 1-\lambda_{p}$ governs the degree of substitution between types of goods. The representative firm takes the price of final goods, $P_{t}$, and the price of retail goods, $P_{t}(i)$, as given. Profit maximization leads to the following first order condition (see the Appendix A.6 for derivation);

$$
Y_{t}(i)=\left(\frac{P_{t}(i)}{P_{t}}\right)^{\frac{\lambda_{p}}{1-\lambda_{p}}} Y_{t}
$$

Model setup is based on new Keynesian framework while prices are sticky in a time dependent manner. We assume that firms set prices according to a variant of the mechanism suggested by Calvo (1983). In each period, a retailer faces a constant probability, $0<1-\xi_{p}<1$, of being able to reoptimize its nominal price. The ability to reoptimize its price is independent across firms and time. Firms that cannot reoptimize their price simply index to lagged inflation. The $i^{\text {th }}$ retailer's problem is:

$$
\max _{\left\{\bar{P}_{t}(i)\right\}} E_{t} \sum_{s=0}^{\infty}\left(\beta \xi_{p}\right)^{s} \Lambda_{t+s}\left[P_{t+s}(i) Y_{t+s}(i)-P_{t+s}^{w} Y_{t+s}(i)\right]
$$

subject to the demand curve (38), with

$$
P_{t}(i)=\left\{\begin{array}{ccc}
\bar{P}_{t}(i) & \text { if } & t=0 \\
\bar{P}_{t}(i) \Pi_{k=1}\left(\pi_{t+k-1}\right)^{l p}(\pi)^{1-l p} & \text { if } & t=1,2, \ldots
\end{array}\right.
$$


where $\pi$ is inflation and $l p \in[0,1]$ indicates the degree of indexation to past prices, for firms which are not allowed to re-optimize.

Therefore, the criterion facing a firm presented with the opportunity to reprice, when $P_{t+s}(i)$ is expressed as $P_{t+s}(i)=P_{t}(i) \Pi_{t, t+s}^{p}$ and with substituting the $P_{t+s}(i)$ and $Y_{t+s}(i)$, is given by (see the Appendix A.7 for derivation);

$$
\max _{\left\{\bar{P}_{t}(i)\right\}} E_{t} \sum_{s=0}^{\infty}\left(\beta \xi_{p}\right)^{s} \Lambda_{t+s} Y_{t+s} P_{t+s}\left[\left(\frac{\bar{P}_{t}(i) \Pi_{t, t+s}^{p}}{P_{t+s}}\right)^{\frac{1}{1-\lambda_{p}}}-p_{t+s}^{w}\left(\frac{\bar{P}_{t}(i) \Pi_{t, t+s}^{p}}{P_{t+s}}\right)^{\frac{\lambda_{p}}{1-\lambda_{p}}}\right]
$$

Consequently, the first-order condition associated to the profit is (see the Appendix A.8 for derivation);

$$
0=E_{t} \sum_{s=0}^{\infty}\left(\beta \xi_{p}\right)^{s} \Lambda_{t+s} P_{t+s} \frac{Y_{t+s}(i)}{1-\lambda_{p}}\left[\left(\frac{\bar{P}_{t}(i) \Pi_{t, t+s}^{p}}{P_{t+s}}\right)-\lambda_{p} p_{t+s}^{w}\right]
$$

As a result the price-level in our models evolves in the following way, in which dividing through by $P_{t-1}$ and rearranging yields the relative price of optimizers as an increasing function of the inflation rate (see the Appendix A.9 for derivation);

$$
\begin{aligned}
& P_{t,} \frac{1}{1-\lambda_{p}}=\left(1-\xi_{p}\right) \bar{P}_{t} \frac{1}{1-\lambda_{p}}+\xi_{p}\left[\left(\pi_{t-1}\right)^{l p}(\pi)^{1-l p} P_{t-1}\right]^{\frac{1}{1-\lambda_{p}}} \\
& \bar{p}_{t}=\left(\frac{1-\xi_{p}\left(\Pi_{t-1, t}^{p}\right)^{\frac{1}{1-\lambda_{p}}}}{1-\xi_{p}}\right)^{1-\lambda_{p}} \equiv \bar{p}\left(\pi_{t}\right)
\end{aligned}
$$

Following the price-setting maximization problem in equation (41), we can transform the price setting condition as follows.

$$
\begin{aligned}
& F_{p, t}=E_{t} \sum_{s=0}^{\infty}\left(\beta \xi_{p}\right)^{s} \hat{\lambda}_{t+s} \frac{\hat{Y}_{t+s}}{1-\lambda_{p}}\left(\bar{\Pi}_{t, t+s}^{p}\right)^{\frac{1}{1-\lambda_{p}}}, \quad A_{t+s}=\hat{\lambda}_{t+s} \frac{\hat{Y}_{t+s}}{1-\lambda_{p}} \\
& K_{p, t}=E_{t} \sum_{s=0}^{\infty}\left(\beta \xi_{p}\right)^{s} \hat{\lambda}_{t+s} \frac{\hat{Y}_{t+s} \lambda_{p} p_{t+s}^{w}}{1-\lambda_{p}}\left(\bar{\Pi}_{t, t+s}^{p}\right)^{\frac{\lambda_{p}}{1-\lambda_{p}}} \\
& \bar{\rho}\left(\pi_{t}\right)=\frac{K_{p, t}}{F_{p, t}}
\end{aligned}
$$

\subsection{Investment Goods Firms}

There are competitive investment goods producers with the $\mathrm{CEE}^{1}$ investment adjustment costs. They produce investment goods from final goods subject to adjustment costs and sell those to wholesale firm with price $P_{t}^{I}$ (see, Christiano et al., 2005; Gertler and Kiyotaki, 2011). The objective function of a capital producer is to choose $I_{t}$ to solve:

$$
\max _{\left\{I_{t}\right\}} E \sum_{t=0}^{\infty} \beta^{t} \frac{\Lambda_{t+s}}{\Lambda_{t}}\left\{P_{t+s}^{I} I_{t+s}-\left[1+\frac{S^{\prime \prime}}{2}\left(\frac{I_{t+s}}{I_{t+s-1}}-z\right)^{2}\right] P_{t+s} I_{t+s}\right\} \quad S^{\prime \prime}>0
$$

where $z$ is the steady-state growth rate of aggregate investment, $S^{\prime \prime}$ is the adjustment cost. The optimal level of investment goods satisfies the first-order condition:

\footnotetext{
${ }^{1}$ Christiano, Eichenbaum and Evans (2005)
} 


$$
P_{t}^{I}=1+\frac{S^{\prime \prime}}{2}\left(\frac{I_{t}}{I_{t-1}}-z\right)^{2}+S^{\prime \prime}\left(\frac{I_{t}}{I_{t-1}}-z\right) \frac{I_{t}}{I_{t-1}}-\beta E_{t} \frac{\Lambda_{t+1}}{\Lambda_{t}} S^{\prime \prime}\left(\frac{I_{t+1}}{I_{t}}-z\right)\left(\frac{I_{t+1}}{I_{t}}\right)^{2}
$$

\subsection{Government and Central Bank}

This model also contains central bank and government. The government in this economy spends resources on government consumption of final goods and its aim is to keep balanced budget every period. The central bank is dependent on government. Hence, we cannot model government and central bank in the separate sections.

We assume that international trade in Iran depends on oil market and it is one of the sources for financing the government budget. Iranian economy is a price taker and its international trade is limited to oil exports. Therefore, the inclusion of oil revenues in the model like most of general equilibrium models for oil-producing countries follows the first order autoregresive process.

$$
\operatorname{Ln}\left(\text { or }_{t}\right)=\left(1-\rho_{o r}\right) \operatorname{Ln}(\overline{o r})+\rho_{o r} \operatorname{Ln}\left(o r_{t-1}\right)+e_{o r, t}
$$

where $\varepsilon_{o r, t} \sim$ i.i.d.N $\left(0, \sigma_{o r}^{2}\right)$ denotes the oil revenue shock, $\overline{o r}$ is the steady-state amount of oil income.

Due to the structure of the Iranian economy, the monetary authority applies in a way that the oil revenues implicitly impact the monetary condition. The growth rate of money is considered the first order autoregresive process. In addition, oil income shocks can affect the planned growth rate of money. In other words, the growth rate of the money can be displayed as follows;

$$
\begin{gathered}
\frac{M_{t+1}}{P_{t+1}}=g_{m, t} \frac{M_{t}}{P_{t+1}}=m_{t+1}^{r}=\frac{g_{m, t}}{\pi_{t+1}} m_{t}^{r} \\
\operatorname{Ln}\left(g_{m, t}\right)=\left(1-\rho_{m p}\right) \operatorname{Ln}\left(\bar{g}_{m}\right)+\rho_{m p} \operatorname{Ln}\left(g_{m, t-1}\right)+\vartheta e_{o r . t}+e_{m p, t}
\end{gathered}
$$

where $g_{m, t}$ and $m_{t}^{r}$ denote the nominal money growth and real money balances, respectively. Moreover, $\varepsilon_{m p, t} \sim$ i.i.d.N $\left(0, \sigma_{m p}^{2}\right)$ shows a monetary policy shock, $\vartheta$ represents the effect of oil revenue shocks on money growth in Iranian economy.

The government expenditure and subsidies are financed through lump-sum taxation to households, oil income and issuing money; therefore, the government runs a balanced budget every period as,

$$
G A_{t}=\frac{T_{t}}{P_{t}}+\frac{M_{t}-M_{t-1}}{P_{t}}+\frac{o r_{t}}{P_{t}}
$$

Government conducts fiscal policy and sets the amount of expenditure $G A_{t}$ according to $A R(1)$ process:

$$
\ln \left(G A_{t}\right)=\left(1-\rho_{g}\right) \ln (\overline{G A})+\rho_{g} \ln \left(G A_{t-1}\right)+\varepsilon_{g, t}
$$

The expression $\varepsilon_{g, t}$ denotes an iid normal government spending shock with mean zero and standard deviation $\sigma_{g}^{2}$. In the model, the supply of nominal bonds is fixed at zero.

\subsection{Bubble}

Following Miao et al. (2013), a sentiment shock $\theta_{t}$ is interduced to model households' beliefs about the fluctuations in bubbles. Households are assumed to believe that the relative size of the bubbles at date $t+\tau$ for any two firms born at date $t$ and $t+1$ evolves according to

$$
\frac{\bar{b}_{t+\tau, \tau}}{\bar{b}_{t+\tau, \tau-1}}=\theta_{t} \quad \bar{b}_{t, 0} \equiv b_{t}^{*}, \quad \tau \geq 1
$$

where $\bar{b}_{t, \tau} \equiv \bar{B}_{t, \tau}^{j} / P_{t}$ denote the real average bubble of firm with age $\tau$ in period $t$. Then $\theta_{t}$ follows an exogenously 
given process:

$$
\ln \left(\theta_{t}\right)=\rho_{\theta} \ln \left(\theta_{t-1}\right)+\varepsilon_{\theta, t}, \quad 0 \leq \rho_{\theta}<1
$$

where $\varepsilon_{\theta, t} \sim$ i.i.d.N $\left(0, \sigma_{\theta}^{2}\right)$. Following Miao et al. (2013) and Ikeda (2013), household beliefs about the movement of bubbles may change randomly over time. It evolves as,

$$
\bar{b}_{t, 0}=b_{t}^{*}, \quad \bar{b}_{t, 1}=\theta_{t-1} b_{t}^{*}, \quad \bar{b}_{t, 2}=\theta_{t-1} \theta_{t-2} b_{t}^{*}, \ldots ., \bar{b}_{t, \tau}=\prod_{k=1}^{\tau} \theta_{t-k} b_{t}^{*}
$$

It is clear from the equation that the sizes of new bubbles, $b_{t}^{*}$ and old bubbles, $\bar{b}_{t, \tau}$ are linked by the sentiment shock. The sentiment shock affects current bubbles relative to a newly born bubble in next period.

In the paper following Miao et al. (2013) and Ikeda (2013), the total bubble born in period $t$ with probability $\delta_{e}$, which implies the firms with bubble in its stock price and exit the market, is given by:

$$
\begin{aligned}
& b_{t}=\sum_{\tau=0}^{t}\left(1-\delta_{e}\right)^{\tau} \delta_{e} \bar{b}_{t, \tau}=\sum_{\tau=0}^{t}\left(1-\delta_{e}\right)^{\tau} \delta_{e}\left(\prod_{k=1}^{\tau} \theta_{t-k}\right) b_{t}^{*}= \\
& \delta_{e} b_{t}^{*}+\left(1-\delta_{e}\right) \delta_{e} \theta_{t-1} b_{t}^{*}+\left(1-\delta_{e}\right)^{2} \delta_{e} \theta_{t-1} \theta_{t-2} b_{t}^{*}+\ldots=m_{t} b_{t}^{*}
\end{aligned}
$$

where,

$$
m_{t}=m_{t-1}\left(1-\delta_{e}\right) \theta_{t-1}+\delta_{e}
$$

The bubble is stationary in the neighborhood of steady state as long as $\left(1-\delta_{e}\right) \theta<1$. From (36), (57) the total bubble evolves according to,

$$
b_{t}=\left(1-\delta_{e}\right) E_{t} \beta \frac{\Lambda_{t+1} P_{t+1}}{\Lambda_{t} P_{t}} \frac{m_{t}}{m_{t+1}} \theta_{t} b_{t+1}\left(1+G_{t+1}\right)
$$

Equations (58) and (59) show that a sentiment shock $\theta_{t}$ affects the relative size $m_{t}$ and hence the total bubble. ${ }^{2}$

\subsection{Ramsey Equilibrium}

A Ramsey planner chooses an allocation and nominal interest rates among those satisfying equilibrium conditions (without a monetary policy rule) to maximize the average household's utility. I follow Schmitt-Grohe and Uribe (2005) to solve for a Ramsey equilibrium. In this case a policy instrument is nominal interest rates, $R_{t}$. Let $x_{t}$ and $S_{t}$ denote endogenous variables and exogenous predetermined variables respectively. The competitive equilibrium conditions in this economy can be written as

$$
E_{t} C\left(x_{t-1}, x_{t}, x_{t+1}, s_{t}, s_{t+1}, R_{t}\right)=0
$$

The period -t objective function of the Ramsey planner is written as

$$
\begin{aligned}
U\left(x_{t-1}, x_{t}, s_{t}\right) & \equiv \int_{0}^{1}\left[\log \left(C_{t+s}-h C_{t+s-1}\right)-\psi_{L} \frac{L_{t+s, j}^{1+v}}{1+v}\right] d j \\
& =\int_{0}^{1}\left[\log \left(C_{t+s}-h C_{t+s-1}\right)-\psi_{L} \frac{\left(\frac{W_{t+s}(j)}{W_{t+s}}\right)^{\frac{\lambda_{w, t}(1+v)}{1-\lambda_{w, t}}} L_{t+s}{ }^{(1+v)}}{1+v}\right] d j \\
& =\left[\log \left(C_{t+s}-h C_{t+s-1}\right)-\psi_{L} \frac{\left.w_{L, t}^{*} \frac{\lambda_{w, t}(1+v)}{1-\lambda_{w, t}} w_{t}^{* \frac{\lambda_{w, t}(1+v)}{1-\lambda_{w, t}}} L_{t+s}^{*}{ }^{(1+v)}\right]}{1+v}\right]
\end{aligned}
$$

where

\footnotetext{
${ }^{2}$ A firm whose stock price has been inflated by a bubble is able to borrow more than firms whose stock price is not inflated. The additional borrowing allows firm to take advantage of high return of investment available and to make more profits if it is hit by a great idiyosyncratic shock in the next period. These additional benefits are summarized by in equation (59).
} 


$$
\begin{aligned}
w_{L, t}^{*}= & {\left.\left.\left.\left.\left[\int_{0}^{1}\left(\frac{W_{t+s}(j)}{W_{t+s}}\right)\right]^{\frac{\lambda_{w}(1+v)}{1-\lambda_{w}}} d j\right]^{\frac{1-\lambda_{w}}{\lambda_{w(1+v)}}}\right]^{\frac{\lambda_{w}(1+v)}{1-\lambda_{w}}} d j+\int_{\xi_{w}}\left(\frac{W_{t+s}(j)}{W_{t+s}}\right)^{\frac{\lambda_{w}(1+v)}{1-\lambda_{w}}} d j\right]^{\frac{1-\lambda_{w}}{\lambda_{w(1+v)}}}\right]^{\left.\frac{W_{t+s}(j)}{W_{t+s}}\right)^{\frac{1-\lambda_{w}}{\lambda_{w(1+v)}}}} } \\
= & {\left[\int_{1-\xi_{w}}\left(1-\xi_{w}\right) \bar{W}_{t} \frac{\lambda_{w}(1+v)}{1-\lambda_{w}}+\xi_{w}\left[w_{L, t-1}^{*} \frac{\left.w_{t-1} \tilde{\Pi}\right]^{\frac{\lambda_{w}(1+v)}{1-\lambda_{w}}}}{w_{t}}\right]^{\frac{\lambda_{w}(1+v)}{1-\lambda_{w}}}\right]^{\frac{1-\lambda_{w}}{\lambda_{w(1+v)}}} } \\
= & {\left[\left(1-\xi_{w}\right) \bar{W}_{t}^{\frac{\lambda_{w}(1+v)}{1-\lambda_{w}}}+\xi_{w}\left[w_{L, t-1}^{*} \frac{w_{t-1}}{w_{t}} \frac{\left(\pi_{t-1}\right)^{l w}(\pi)^{1-l w}}{\pi_{t}}\right.\right.}
\end{aligned}
$$

The Ramsey planner chooses $f_{t}=\left[x_{t}^{\prime}, R_{t}\right]^{\prime}$ to maximize the discounted sum of period utility. The portion of the Lagrangean associated with the Ramsey planner's optimization problem that is relevant for the purpose of computing optimal policy from the timeless perspective is given by

$$
\begin{aligned}
L= & \ldots+U\left(x_{t-1}, x_{t}, s_{t}\right)+\beta E_{t} U\left(x_{t}, x_{t+1}, s_{t+1}\right)+\beta^{-1} \lambda_{t-1}^{\prime} C\left(x_{t-2}, x_{t-1}, x_{t}, s_{t-1}, s_{t}, R_{t-1}\right) \\
& +E_{t} \lambda_{t}^{\prime} C\left(x_{t-1}, x_{t}, x_{t+1}, s_{t}, s_{t+1}, R_{t}\right)+\beta E_{t} \lambda_{t+1}^{\prime} C\left(x_{t}, x_{t+1}, x_{t+2}, s_{t+1}, s_{t}, R_{t+1}\right)+\ldots
\end{aligned}
$$

The first-order condition of the problem with respect to $f_{t}$ is

$$
\frac{\partial U(t)}{\partial f_{t}^{\prime}}+\beta E_{t} \frac{\partial U(t+1)}{\partial f_{t}^{\prime}}+\beta^{-1} \lambda_{t-1}^{\prime} \frac{\partial C(t-1)}{\partial f_{t}^{\prime}}+\lambda_{t}^{\prime} \frac{\partial C(t)}{\partial f_{t}^{\prime}}+\beta E_{t} \lambda_{t+1}^{\prime} \frac{\partial C(t+1)}{\partial f_{t}^{\prime}}=0
$$

Where $U(t) \equiv U\left(x_{t-1}, x_{t}, s_{t}\right)$ and $C(t) \equiv C\left(x_{t-1}, x_{t}, x_{t+1}, s_{t}, s_{t+1}, R_{t}\right)$.

\subsection{Loss Function}

As Bernanke and Gutler (1999) explain, the quantitative criteria used to assess the policy rule's performance are the unconditional variances of output and inflation, which are obtained by simulating the model for alternative policy regimes. These criteria are consistent with the formal quadratic loss function. The central bank minimizes the loss function to drive the appropriate policy responses to economic fluctuations. Following Boostani (2013), we use the equation as follows,

$$
\operatorname{Var}\left(Y_{t}\right)+\lambda_{1} \operatorname{Var}\left(\pi_{t}\right)
$$

\subsection{Aggregation and Equilibrium}

Aggregating $L_{t}^{j}$, given by (21), over idiosyncratic shocks, $\varepsilon_{t}^{j}$ yields the demand for labor as follows;

$$
\bar{L}_{t}^{j}=(1-\alpha)^{\frac{1}{\alpha}}\left(\frac{P_{t}^{w} A_{t}^{1-\alpha}}{W_{t}}\right)^{\frac{1}{\alpha}}\left[\Phi\left(\varepsilon_{t}^{*}\right)+\int_{\varepsilon \geq \varepsilon_{t}^{*}}\left(\frac{\varepsilon_{t}^{*}}{\varepsilon}\right)^{\frac{1}{\alpha}} d \Phi(\varepsilon)\right] K_{t}^{j}
$$

Aggregating demand for labor over j yields;

$$
L_{t}=\int_{j} \bar{L}_{t}^{j} d j=(1-\alpha)^{\frac{1}{\alpha}}\left(\frac{P_{t}^{w} A_{t}^{1-\alpha}}{W_{t}}\right)^{\frac{1}{\alpha}}\left[\Phi\left(\varepsilon_{t}^{*}\right)+\int_{\varepsilon \geq \varepsilon_{t}^{*}}\left(\frac{\varepsilon_{t}^{*}}{\varepsilon}\right)^{\frac{1}{\alpha}} d \Phi(\varepsilon)\right] K_{t}
$$

where the demand for labor, $L_{t}$, must be equal to its supply, $L_{t}^{*}$.

$$
\int_{j} \bar{L}_{t}^{j} d j=\int_{0}^{1} L_{t}(i) d i=L_{t}^{*}
$$


Aggregating output over an idiosyncractic shock $\varepsilon_{t}^{j}$ yields (see the Appendix A.10 for derivation),

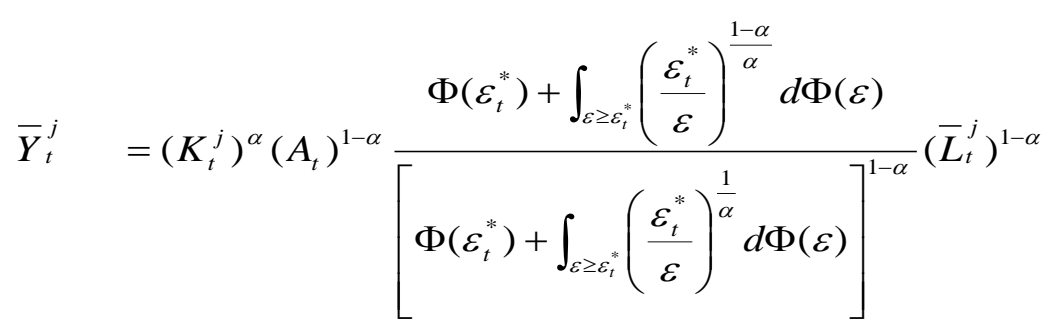

Aggregating over j yields;

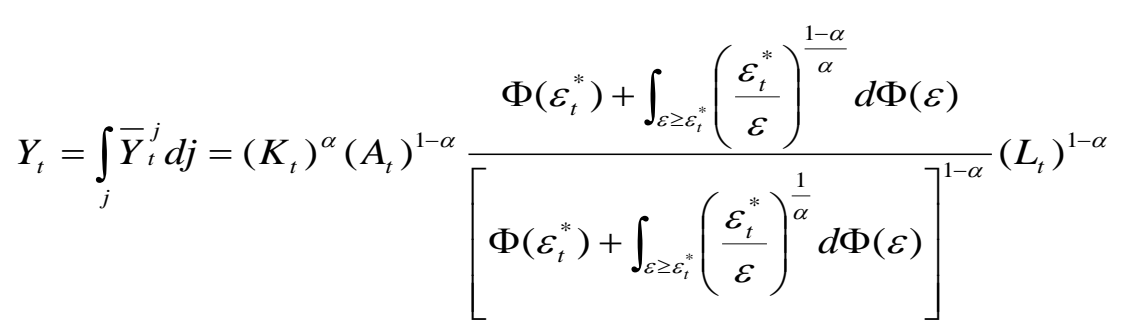

Where the supply of whole sale good, $Y_{t}^{*}$,must be equal to its demand, $Y_{t}$;

$$
\int_{j} \bar{Y}_{t}^{j} d j=\int_{0}^{1} Y_{t}(i) d i=Y_{t}^{*}
$$

Aggregating investment over an idiosyncractic shock $\varepsilon_{t}^{j}$ yields

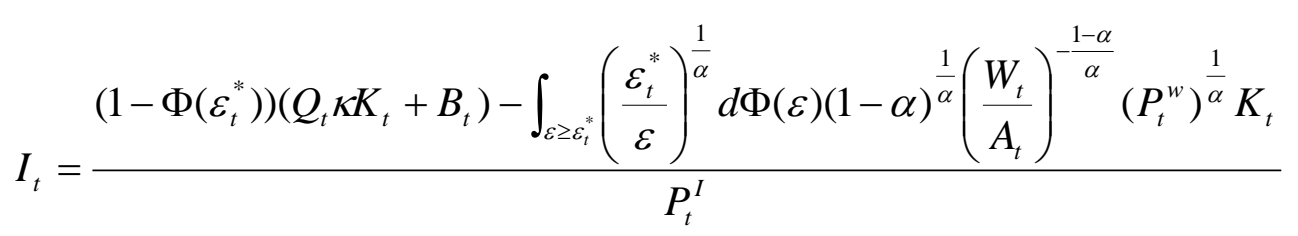

As Ikeda expressed, the first term in equation (71) describes the amount of borrowing of wholesale goods firms and the second term denotes the amount of borrowing assigned to working capital for firms conducting investment. Therefore, this equation represents the amount of investment in final goods.

Following Ikeda (2013), there are newly born firms that collect a fraction $\varphi$ of capital stock accumulated by exit firms. Then, the aggregate capital stock of all firms in the end of period $t$ after the realization of an exit shock is

$$
K_{t+1}=\left(1-\delta_{e}+\delta_{e} \varphi\right) K_{t+1}^{\prime}
$$

$K_{t+1}^{\prime}$ denotes the capital stock in the end of period $t$ before the realization of the exit shock, is given by;

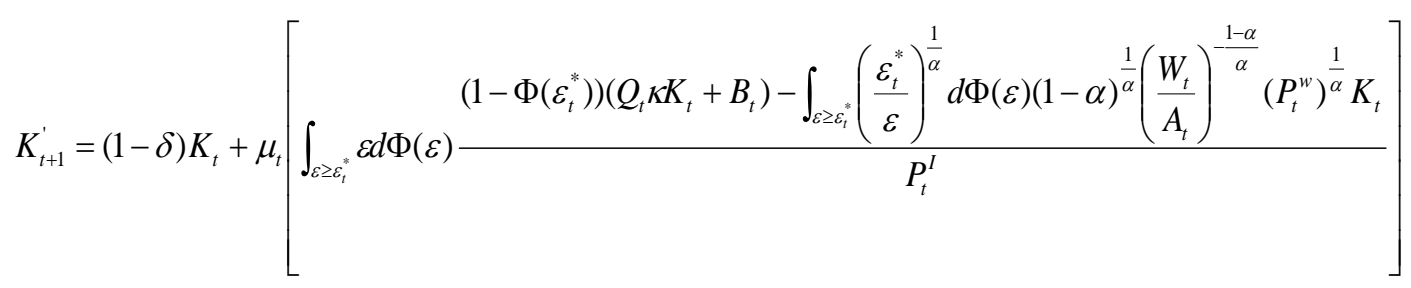

A competitive equilibrium consists of stochastic processes of 26 aggregate endogenous

variables, $C_{t}, M_{t}^{d}, \lambda_{t}, R_{t}, \bar{W}_{t}, w_{t}, F_{w}, K_{w}, P_{t}^{w}, \varepsilon_{t}^{*}, Q_{t}, \bar{P}_{t}, \pi_{t}, F_{p}, K_{p}, P_{t}^{I}, o r_{t}, m_{t}^{r}, g_{m, t}, G A_{t} m_{t}$ $b_{t}, L_{t}^{*}, Y_{t} I_{t}, K_{t}$, which satisfies (3), (4), (5), (6), (10), (11), (12), (13), (20), (30), (35), (43), (44), (45), (46), (48), (49), (50), (51), (53), (58), (59), (65), (69), (71) and (73). 


\section{Data and Calibrated Parameters}

Our model is stationary in the growth rate of total factor productivity (TFP) shock, we transform the equilibrium system into a stationary one. Moreover, we use a calibrated model to fit the model for Iranian data. Our model has five shocks: the TFP shock, the monetary policy shock, the government spending shock, the sentiment shock and the oil revenue shock.

We calibrate some of the parameters of the model. Some key parameters is evaluated based on previous studies suck as Ikeda (2013), Miao et al. (2013) and some are based on authors for maximum compatibility simulated data with real data. In brief, Table (1) and (2) present the values assigned to the calibrated parameters.

Table1. Key Parameters

\begin{tabular}{cccc}
\hline Parameters & Explanation & Value & Resource \\
\hline$\delta e$ & Exit rate of firms & 0.01 & Ikeda (2013) \\
$\varepsilon^{-\eta}$ & Fraction of firms investing in SS & 0.17 & Ikeda (2013) \\
$\kappa$ & Credit constraint & 0.11 & Ikeda (2013) \\
$\beta$ & Preference discount rate & 0.99 & Boostani (2013) \\
$\nu$ & Inverse Frisch elasticity & 2.17 & Taee (2007) \\
$\lambda_{p}$ & Price markup & 1.15 & Ikeda (2013) \\
$\lambda_{w}$ & Wage markup & 1.15 & Ikeda (2013) \\
$\rho_{z}$ & TFP growth shocks, AR & 0.92 & Afshari et. al (2014) \\
$\sigma_{q}$ & weights associated with utility of money-holdings & 1.32 & Davoodi and Zarepour (2007) \\
\hline
\end{tabular}

Table 2. Key Parameters with Authors

\begin{tabular}{|c|c|c|c|}
\hline Parameters & Explanation & Value & Explanation \\
\hline$\alpha$ & Capital income share & 0.38 & $\mathrm{C} / \mathrm{Y}$ is equal to 0.53 \\
\hline$\delta$ & Capital depreciation rate & 0.05 & $\mathrm{I} / \mathrm{Y}$ is equal to 0.24 \\
\hline$S^{\prime \prime}$ & Investment adjustment costs & 0.1 & $\mathrm{I} / \mathrm{Y}$ is equal to 0.24 \\
\hline$\pi$ & SS quarterly inflation & 1.0041 & In data \\
\hline$\varphi$ & Start-up capital & 1 & In Model \\
\hline$z$ & SS TFP growth rate & 1 & In Model \\
\hline$h$ & Consumption habit & 0.8 & In data \\
\hline$\xi_{p}$ & Calvo prices & 0.5 & In Model \\
\hline$\xi_{w}$ & Calvo wages & 0.75 & In Model \\
\hline$l p$ & Price indexation & 0.5 & In Model \\
\hline$l w$ & Wage indexation & 0.5 & In Model \\
\hline$\rho_{m p}$ & Monetary policy shocks, AR & 0.29 & $A R(1)$ process \\
\hline$\rho_{g}$ & Government spending shocks, AR & 0.11 & $A R(1)$ process \\
\hline$\rho_{o r}$ & Oil revenue shocks, AR & 0 & $A R(1)$ process \\
\hline$\rho_{\theta}$ & Sentiment shocks, AR & 0.82 & St.D of PS is 19 \\
\hline$\vartheta$ & effect of oil revenue shocks on money growth & 0.001 & $A R(1)$ process \\
\hline$\underline{m}^{r}$ & SS amount of real money balances & 1 & In Model \\
\hline$g_{m}$ & SS amount of nominal money growth & 1.0041 & In data \\
\hline or & SS amount of oil income & 0.071 & $\mathrm{Oil} / \mathrm{G}$ is equal to 0.46 \\
\hline$\overline{G A}$ & SS government expenditure & 0.15 & $\mathrm{G} / \mathrm{Y}$ is equal to 0.13 \\
\hline$L$ & Log hours in SS & 0.28 & In Model \\
\hline$\delta_{z}$ & TFP growth shocks, Std & 0.004 & St.D of I is 6.24 \\
\hline$\delta_{m p}$ & Monetary policy shocks, Std & 0.01 & Residual of $A R(1)$ process \\
\hline$\delta_{g}$ & Government spending shocks, Std & 0.046 & Residual of $A R(1)$ process \\
\hline$\delta_{\theta}$ & Sentiment shocks, Std & 0.03 & St.D of PS is 19 \\
\hline$\delta_{o r}$ & Oil revenue shocks, Std & 0.5 & Residual of $A R(1)$ process \\
\hline
\end{tabular}




\section{Results}

The model's empirical implications based on the calibrated parameters are computed using the simulated data $(20,000$ periods). This paper uses quarterly data of the Iranian economy covering the period of 1986-2012. All series are logged and detrended with the HP filter. The columns labeled $Y, C, I, \mathrm{G}, P S$, Oil and $M$ refer, respectively, to real per capita GDP, real per capita consumption, real per capita investment, real per capita government expenditure, real per capita oil income, real per capita stock prices and real per capita money balances.

We present the ratio of actual and simulated variables relative to $\mathrm{Y}$ in Table (3). As Table (3) indicates, the estimated model fits the empirical moments from the actual data quite well.

Table 3. The Ratio of real economic and simulated variables relative to $\mathrm{Y}$

\begin{tabular}{lcccc}
\hline & $\mathrm{C} / \mathrm{Y}$ & $\mathrm{I} / \mathrm{Y}$ & $\mathrm{G} / \mathrm{Y}$ & Oil/G \\
\hline Data & 0.5376 & 0.2452 & 0.1300 & 0.4688 \\
Baseline Model & 0.6033 & 0.2149 & 0.1817 & 0.4733 \\
\hline
\end{tabular}

Source: Authors calculation

Table 4. Business Cycles Statistics (In Percent)

\begin{tabular}{lccccc}
\hline \multicolumn{7}{c}{ Standard Deviations } & & \\
\hline & Y & C & I & G & PS \\
Data & 2.71 & 3.16 & 6.24 & 4.62 & 19.99 \\
Baseline Model & 3.03 & 3.56 & 6.92 & 4.60 & 10.00 \\
Optimal Monetary Policy & 2.86 & 3.24 & 7.06 & 4.63 & 10.08 \\
\hline \multicolumn{7}{c}{ Standard Deviations Relative to Y } \\
\hline Data & 1.00 & 1.16 & 2.30 & 1.70 & 7.33 \\
Baseline Model & 1.00 & 1.17 & 2.28 & 1.52 & 3.29 \\
Optimal Monetary Policy & 1.00 & 1.13 & 2.46 & 1.61 & 3.52 \\
\hline \multicolumn{7}{c}{ Correlation with Y } \\
\hline Data & 1.00 & 0.50 & 0.77 & 0.32 & 0.32 \\
Baseline Model & 1.00 & 0.85 & 0.67 & 0.23 & 0.82 \\
Optimal Monetary Policy & 1.00 & 0.82 & 0.68 & 0.25 & 0.88 \\
\hline
\end{tabular}

Source: Authors calculation

To evaluate our model performance, we present in Table 4 the baseline model's predictions regarding standard deviations, standard deviations relative to output and correlations with output. This table also presents results for the two comparison models. The model moments are computed using the simulated data from the when all shocks are turned on. From Table 4, we observe that our calibrated model fits the empirical moments from the actual data quite well. Moreover, it explains the stock market volatility in the data. Most models in finance or macroeconomics have difficulty in explaining the stock market volatility (Shiller, 1981). Furthermore, the persistence of macroeconomic variables and stock prices are matched as well as their comovements. Our calibrated model with bubbles identifies the sentiment shock and provides a powerful amplification and propagation mechanism for this shock.

We use variance decomposition to evaluate the relative importance of the five structural shocks in driving fluctuations in the stock prices and macroeconomic quantities at the business cycle frequency. Table (5) reports the variance decomposition across the shocks.

Table 5. Variance Decomposition (in percentage)

\begin{tabular}{lcccccc}
\hline & \multicolumn{2}{c}{ Sentiment } & TFP & $\begin{array}{c}\text { Monetary } \\
\text { Policy Shock }\end{array}$ & Oil income & Government \\
Output & & & & & \\
& Baseline Model & 46.37 & 0.42 & 47.46 & 0.12 & 5.63 \\
& Ramsey Optimal Policy & 76.26 & 5.45 & 11.33 & 0.00 & 6.96 \\
\hline Consumption & Baseline Model & 65.20 & 6.87 & 27.66 & 0.07 & 0.20 \\
& Ramsey Optimal Policy & 94.93 & 3.47 & 1.49 & 0.00 & 0.11 \\
\hline Investment & Baseline Model & 8.35 & 17.13 & 72.90 & 0.18 & 1.44 \\
& Ramsey Optimal Policy & 27.15 & 40.55 & 30.89 & 0.00 & 1.41 \\
\hline Stock Price & Baseline Model & 92.43 & 0.50 & 6.98 & 0.02 & 0.07 \\
& Ramsey Optimal Policy & 98.31 & 0.14 & 1.48 & 0.00 & 0.07 \\
\hline
\end{tabular}

Source: Authors calculation 
Table (5) shows that the sentiment shock in baseline model explains about 47, 65 and 8 percent of the fluctuations in output, consumption and investment respectively. The sentiment shock is the dominating force driving the fluctuations in consumption. This is due to the large wealth effect caused by the fluctuations in the stock market value. As Table (5) indicates the sentiment shock accounts for about 92 percent of the stock market fluctuations. The contributions of the other shocks are negligible. Moreover, the sentiment shock in Ramsey equilibrium explains about 76, 95, 27 and 98 percent of the fluctuations in output, consumption, investment and stock price respectively. The optimal monetary policy performs the same as monetary policy rule with money growth in explaining stock price fluctuations.

The money growth shock is important in explaining variations in macroeconomic quantities, but the oil income shock does not explain much of the fluctuations in output, consumption, investment, and stock price. According equation (51), oil income shocks affect money growth and this rise affects on macroeconomic variables much.

The government's consumption shock reports a tiny fraction of fluctuations in stock prices, investment, consumption, except output.

The TFP shock plays a critical role on economic fluctuations at business cycle frequencies. The TFP shock is correlated with consumption and investment. However, it does not explain much of the fluctuations in output and stock price. TFP shock due to changes in the marginal product of capital and labor will cause households to optimally respond to these changes. This release mechanism led to changes in the economy. While a change in government spending makes no transition mechanism and the effects of government spending shock in the economy is limited. The TFP shock in optimal monetary policy explains about 41 percent of the fluctuations in investment and performs differently from monetary policy rule with money growth.

As indicated in Figure (1) and (2), we consider the impulse responses to a one-standard-deviation five structural shocks in driving fluctuations in macroeconomic quantities and stock price at the business cycle frequency.

In the case of positive oil shock, the oil income increases and it leads to budget surplus, increases the output, consumption, inflation, investment, hours worked. It raises marginal $Q$, the bubble and the stock price.

In addition, Figure (1) and (2) shows the response function of macro variables relative to government's consumption shock in base model with money growth. Increasing in government expenditure is the fiscal policy and it raises the output. It causes to money transactions grow and interest rate growth. With decrease of available credit and crowding out effect also reduces investment throughout few quarters.

The prices decline in response to the government consumption shock. It raises the present value of the stream of taxes over time which generates a negative wealth effect that brings down private consumption. The government expenditure shock reduces the marginal $Q$, the bubble and leads to negative effect on the stock price.

From Figure (1), the money growth shock increases demand and leads to increase the output and consumption. It increases inflation and raises the marginal $Q$, the bubble and the stock price. This shock plays a critical role on Iranian economic fluctuations. As indicated in Table (5) in money growth model, it explains much of the fluctuations in output, consumption, investment and stock price after the sentiment shock.

As indicated in Figure (2), a monetary policy shock reduces the output, consumption, inflation, investment, labor hours, the marginal $Q$, the bubble and stock price. Because of the positive interest rate shock the rental rate of capital increases and it leads to reduce the investment and output. Due to this rise, the desire to invest in banks increases and afterward it cause to reduce the stock price. Therefore, the optimal monetary policy responses perform differently from the monetary policy rule with money growth in explaining the impulses of monetary policy shocks.

A Positive TFP shock increases output, labor supply and investment, but it reduces the future marginal utility of consumption due to the wealth effect. TFP shock raises both marginal $Q$ and the bubble, and its net impact on the stock price is positive. It cannot be an important driver of the stock market movements. The occurrence of a positive technology shock, capital and labor productivity goes up. As a result, firms increase demand for labor and capital. And labor income and rental rate of capital increase. The increase in supply of capital and labor leads to production increase.

Figure (1) and (2) presents the impact of a sentiment shock. These Figures plot the responses to a positive sentiment shock under two alternative monetary policy rule including money growth and Ramsey monetary policy respectively. Both monetary policy rules do restrain a stock price boom by raising real interest rates sharply. The responses of the variables such as output, consumption, investment, bubble, marginal Q and stock price in Ramsey monetary policy become close to those under the monetary regimes including money growth. However, the quantities of the increases in real variables such as output, consumption and investment are limited under the monetary policy with money growth, relative to the optimal monetary policy. A positive sentiment shock raises the size of the bubble. It causes the credit constraints to be relaxed. Thus, firms make more investment. As capital accumulation rises, marginal $Q$ falls so that the fundamental value of the stock market also falls. This fall is dominated by the rise in the bubble component, causing the 
stock price to rise on impact, and afterward raise investment. This in turn causes consumption to rise due to the wealth effect and raises output. This result indicates that the sentiment shock can generate a large volatility of the stock market relative to that of consumption, investment, and output. The sentiment shock has a negative impact on inflation. The capital stock rises due to positive sentiment shock, causing the labor hours to rise.

In order to determine the central bank's loss function, we estimate the loss function which is used to assess the policy rule's performance. Table (6) presents the results for the defined function under investigation.

Table 6. The Loss Function

\begin{tabular}{cc}
\hline The Models & Values \\
\hline Baseline Model & 0.00074 \\
Ramsey Optimal Monetary Policy & 0.00006
\end{tabular}

Source: Authors calculation

Table (6) shows that applying Ramsey optimal monetary policy relative to monetary regimes with money growth decreases the central bank loss function.

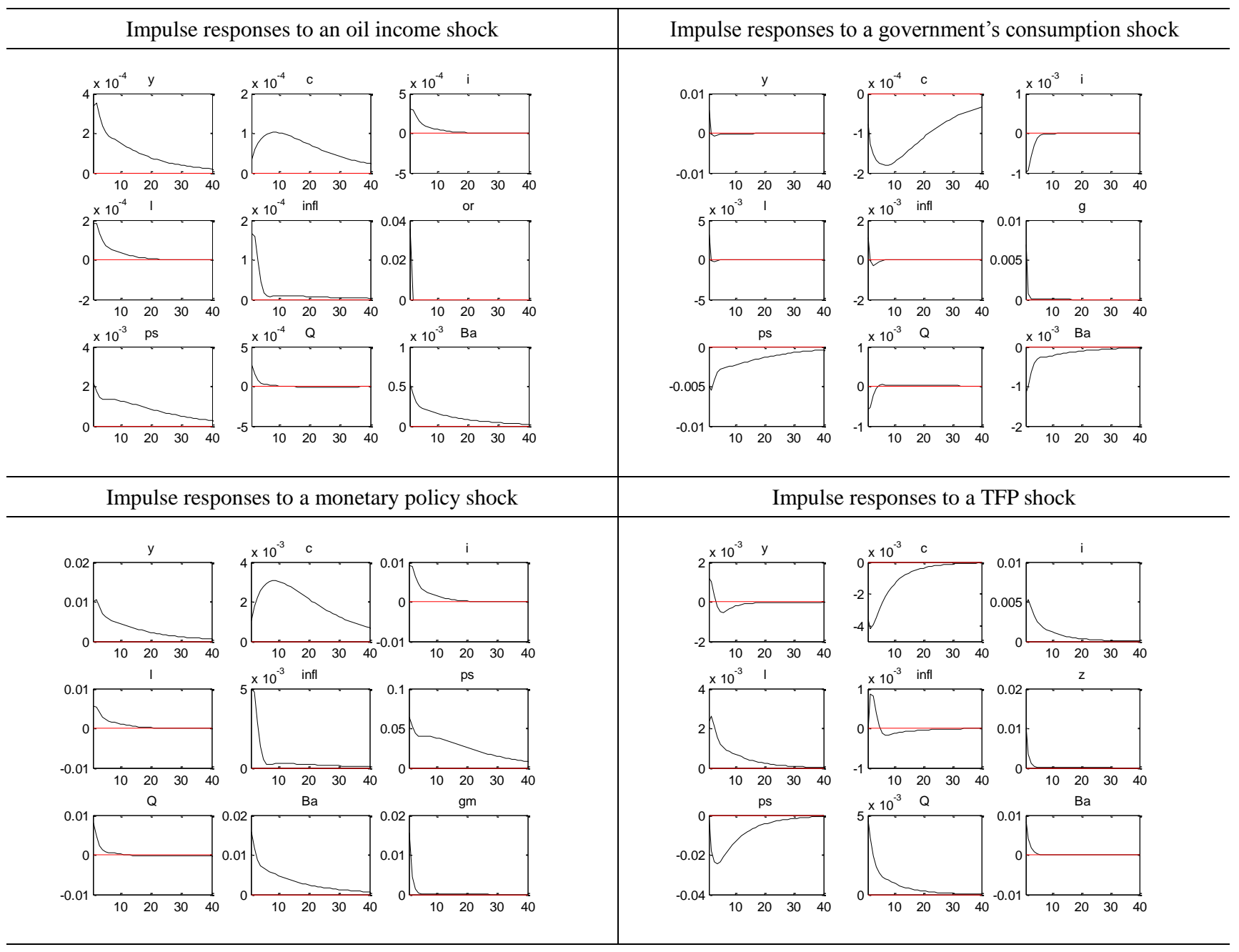

Impulse responses to a sentiment shock 

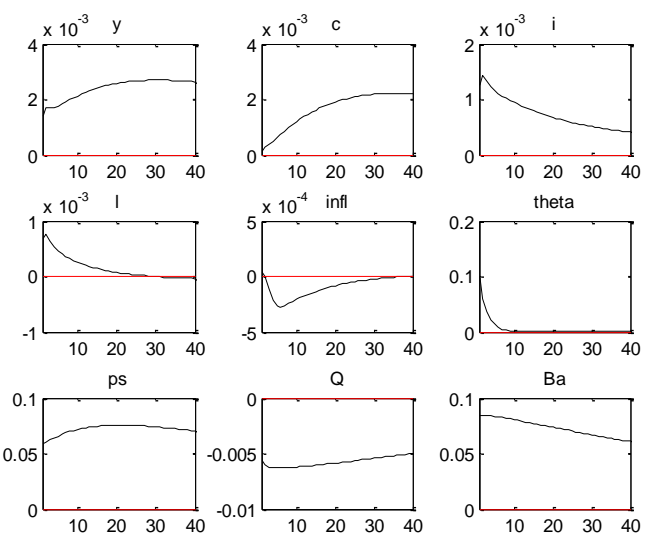

Source: Authors calculation

Figure 1. Impulse responses to a one-standard-deviation oil income shock, government's consumption shock, a monetary policy shock, TFP shock and sentiment shock in the baseline model.

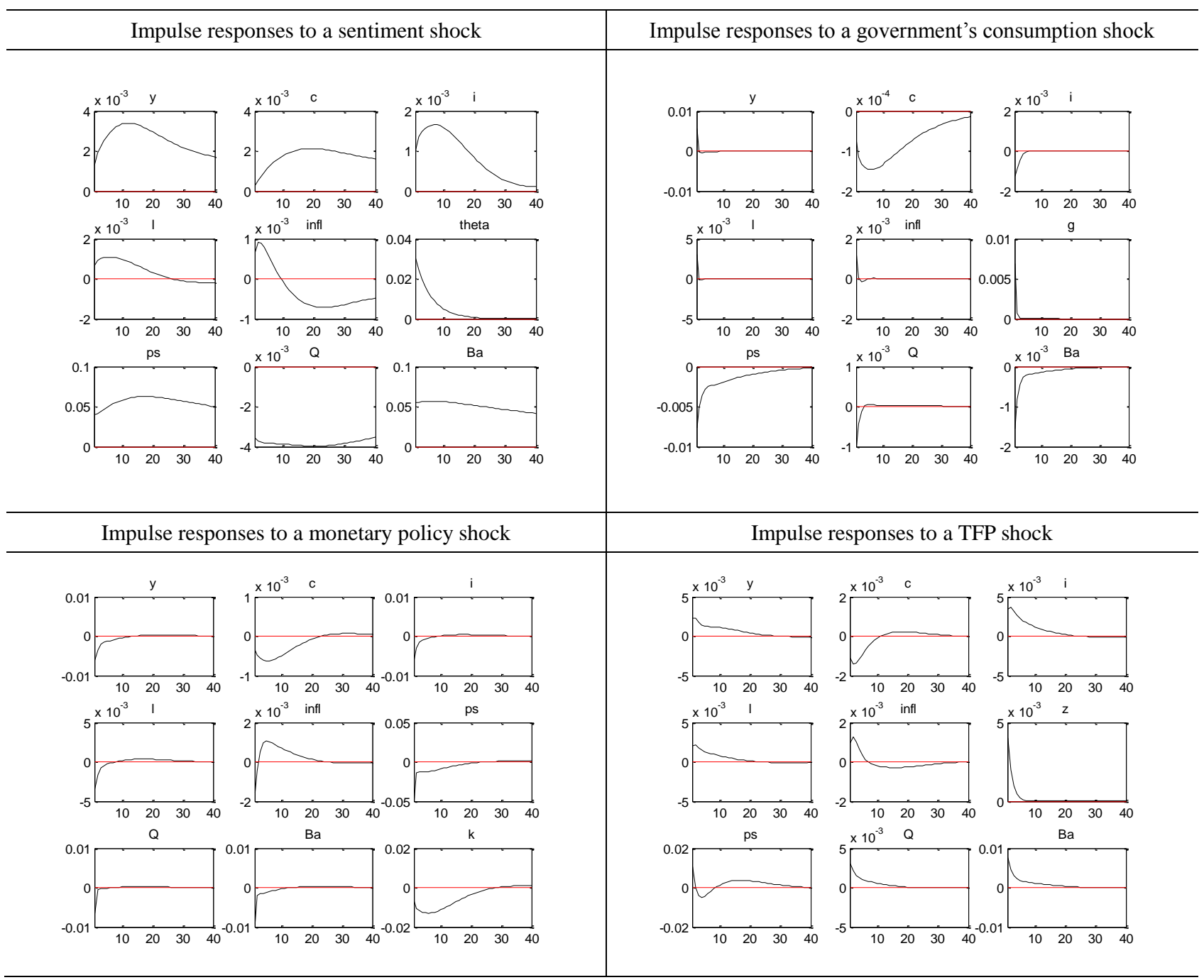

Source: Authors calculation

Figure 2. Impulse responses to a one-standard-deviation government's consumption shock, a monetary policy shock, TFP shock and sentiment shock in the Ramsey Optimal Monetary Policy. 


\section{Conclusion}

Economics as macroeconomic policy objectives focus on full employment, price stability and sustainable economic growth. Economic growth is the most important economic variable that it shows sensitivity than other economic variable changes. Therefore, achieving sustainable economic growth requires the mobilization and allocation of resources at the national level and the development of financial markets.

The role of monetary policy after the financial crisis in 2007-2009, as an example of speculative bubbles in financial markets, due to the economic and social effects of asset price fluctuation and the impact of cyclical fluctuation in economic variables has become an important issue in monetary policy and it is the concern of policymakers.

In recent years there has been increasing interest in modelling rational bubbles in the literature. This paper investigates how the monetary policy should be conducted in a stock market bubble and fluctuation in aggregate variables within a dynamic stochastic general equilibrium (DSGE) model for Iranian economy.

This study models the role of monetary policy including money growth and Ramsey optimal monetary policy in the new Keynesian monetary framework with nominal wage and price rigidities. We set model based on Ikeda (2013) with applying "Money in Utility" approach suitable for Iranian economy to derive optimal monetary policy is used by central banks to reduce the losses.

Bubbles in our model emerge through a positive feedback loop mechanism supported by self-fulfilling beliefs. The sentiment shock, which represents the size of current bubbles relative to newly born bubbles, causing bubbles movement and it transfers to the real economy through endogenous credit constraint. Moreover, this study investigates the impulse and response between sentiment shock and fluctuation in aggregate variables.

In this study, the quarterly data after applying the log transformation, seasonal adjustment and detrended with the HP filter are used for calibration the parameters. We study the oil income shock, in addition to the TFP shock, the monetary policy shock, the government spending shock, the sentiment shock such as study by Ikeda (2013).

Results show that: first, applying Ramsey optimal monetary policy in relative to monetary regimes with money growth decreases the loss function. Second, the sentiment shock drives the movements of stock market fluctuations and variations in real economy, leading to explain the positive contemporaneous correlation between stock prices and the real economy and it explains the business cycles in Iran. Third, the sentiment shock under the optimal monetary policy performs the same as monetary policy rule with money growth in explaining stock price fluctuations. The results of calibrated model revealed a relation between moments of variables in the model and moments of real data in the economy. Therefore, this model can help us to analysis the effect of stock market bubbles on macroeconomic variables in economy.

\section{References}

Afshari, Z., Mahmoodi, N., \& Boostani, R. (2014). Evaluating the Neoclassical Growth Model in Explaining Iranian Business Cycles. Quarterly Journal of Applied Economics Studies in Iran (AESI), 3(9), 189-204. (In Persian)

Bernanke, B. S. (2002). Asset Price Bubbles and Monetary Policy. Speech delivered to the New York Chapter of the National Assocation for Business Economics, New York.

Bernanke, B. S., \& Gertler, M. (1999). Monetary Policy and Asset Price Volatility. Paper presented at Fedral Reserve Bank of Kansas City Annual Conference, Jackson Hole.

Bernanke, B. S., \& Gertler, M. (2001). Should Central Bank Respond to Movement in Asset Prices? The American Economic Review: Papers and Proceedings, 91(2), 253-257.

Bernanke, B. S., \& Kuttner, K. N. (2005). What Explains the Stock Market's Reaction to Federal Reserve Policy? Journal of Finance, 60(3), 1221-1258.

Boostani, R. (2013). The Role of Transitory and Permanent Shocks in Business Cycle. Quarterly Journal of Economic Strategy, 6, 41-58. (In Persian)

Borio, C., \& Lowe, P. (2002). Asset Prices, Financial and Monetary Stability: Exploring the Nexus. BIS Working Papers, 114.

Calvo, G. (1983). Staggered Prices in a Utility Maximizing Framework. Journal of Monetary Economics, 12, 383-398. http://dx.doi.org/10.1016/0304-3932(83)90060-0

Castelnuovo, E., \& Nistico, S. (2010). Stock market conditions and monetary policy in a DSGE model for the U.S. Journal of Economic Dynamics \& Control, 34, 1700-1731.

Cecchetti, S. G., Genberg, H., Lipsky, J., \& Wadhwani, S. (2000). Asset Prices and Central Bank Policy. The Geneva Report on the World Economy, no. 2. ICMB and the CEPR. 
Cecchetti, S. G., Genberg, J., \& Wadhwani, S. (2002). Asset Prices in a Flexible Inflation Targeting Framework. In: Hunter, William C., Kaufman, George G., \& Pomerleano, Michael (eds), Asset Price Bubbles: Implications for Monetary, Regulatory, and International Policies. MIT Press. http://dx.doi.org/10.3386/w8970

Christiano, L. J., Eichenbaum, M., \& Evans, C. L. (2005). Nominal Rigidities and the Dynamic Effects of a Shock to Monetary Policy. Journal of Political Economy, 113(1), 1-45. http://dx.doi.org/10.1086/426038

Christiano, L. J., Ilut, C., Motto, R., \& Rostagno, M. (2008). Monetary Policy and Stock Market Boom-Bust Cycles. European Central Bank, Working Paper Series, No 955.

Christiano, L. J., Ilut, C., Motto, R., \& Rostagno, M. (2010). Monetary Policy and Stock Market Booms. Paper presented at Federal Reserve Bank of Kansas City Annual Conference, Jackson Hole, 85-145.

Davoodi, P., \& Zarepour, Z. (2007). The Role of Definition of Money in the Stability of the Iranian Demand for Money. Iranian Journal of Economic Research, 47-74. (In Persian)

Funke, M., Paetz, M., \& Pytlarczyk, E. (2010). Stock market wealth effects in an estimated DSGE model for Hong Kong. Economic Modelling.

Gali, J. (2011). Monetary Policy and Rational Asset Price Bubbles. manuscript, CREI, University Pompeu Febra, and Barcelona GSE. http://dx.doi.org/10.3386/w18806

Gertler, M., \& Kiyotaki, N. (2010). Financial Intermediation and Credit Policy in Business Cycle Analysis. working paper, NYU.

Ikeda, D. (2013). Monetary Policy and Inflation Dynamics in Asset Price Bubbles. Bank of Japan Working Paper

Kohn, D. L. (2006). Monetary Policy and Asset Prices. Speech at an ECB colloquium on "Monetary Policy: A Journey from Theory to Practice," held in honor of Otmar Issing.

Kohn, D. L. (2008). Monetary Policy and Asset Prices Revisited. speech delivered at the Caton Institute's 26th Annual Monetary Policy Conference, Washington, D.C.

Leijonhufvud, A. (2007). The Perils of Inflation Targeting. VoxEU, http://www.voxeu.org/index.php?q=node/322.

Miao, J., Wang, P., \& Xu, Z. (2013). A Bayesian DSGE Model of Stock Market Bubbles and Business Cycles. manuscript, Boston University and HKUST.

Robinson, T., \& Stone, A. (2006). Monetary Policy, Asset-price Bubbles, and the Zero Lower Bound. Chap. 2, pages 43-81 of: Ito, Takatoshi, \& Rose, Andrew K. (eds), Monetary Policy with Very Low Inflation in the Pacific Rim. NBER East Asia Seminar on Economics, vol. 15. National Bureau of Economic Research.

Roubini, N. (2006). Why Central Banks Should Burst Bubbles. International Finance, 9(1), 87-107.

Schmitt-Grohe, S. and Uribe, M. (2005). Optimal inflation stabilization in a medium-scale macroeconomic model. NBER Working Papers 11854. http://dx.doi.org/10.3386/w11854

Shiller, R. J. (1981). Do Stock Prices Move Too Much to be Justified by Subsequent Changes in Dividends? American Economic Review, 71(3), 421-36. http://dx.doi.org/10.3386/w0456

Taee, H. (2007). An Estimation of Labour Supply Function Using the Iranian Micro Data. Iranian Journal of Economic Research, 29, 93-112. (In Persian)

\section{Appendix}

We present a formal derivation of the model in section 3 . We report them here for completeness.

A wage-setting problem is formulated as follows;

$$
\begin{aligned}
& \max _{\left\{W_{t}(j)\right\}} E_{t} \sum_{s=0}^{\infty}\left(\beta \xi_{w}\right)^{s}\left\{\Lambda_{t+s} W_{t+s}(j) L_{t+s}(j)-\psi_{L} \frac{L_{t+s, j}^{1+v}}{1+v}\right\} \\
& \max _{\left\{W_{t}(j)\right\}} E_{t} \sum_{s=0}^{\infty}\left(\beta \xi_{w}\right)^{s}\left\{\Lambda_{t+s}\left(\frac{W_{t+s}(j)}{W_{t+s}}\right)^{\frac{\lambda_{w}}{1-\lambda_{w}}} W_{t+s}(j) L_{t+s}-\frac{\psi_{L}}{1+v}\left(\frac{W_{t+s}(j)}{W_{t+s}}\right)^{\frac{\lambda_{w}(1+v)}{1-\lambda_{w}}} L_{t+s}{ }^{1+v}\right\} \\
& \max _{\left\{W_{t}(j)\right\}} E_{t} \sum_{s=0}^{\infty}\left(\beta \xi_{w}\right)^{s}\left\{\Lambda_{t+s}\left(\frac{\bar{W}_{t}(j) \Pi_{t, t+s}^{w}}{W_{t+s}}\right)^{\frac{1}{1-\lambda_{w}}} W_{t+s} L_{t+s}-\frac{\psi_{L}}{1+v}\left(\frac{\bar{W}_{t}(j) \Pi_{t, t+s}^{w}}{W_{t+s}}\right)^{\frac{\lambda_{w}(1+v)}{1-\lambda_{w}}} L_{t+s}{ }^{1+v}\right\} \\
& \max _{\left\{W_{t}(j)\right\}} E_{t} \sum_{s=0}^{\infty}\left(\beta \xi_{w}\right)^{s} \Lambda_{t+s}\left\{\left(\frac{\bar{W}_{t}(j) \Pi_{t, t+s}^{w}}{W_{t+s}}\right)^{\frac{1}{1-\lambda_{w}}} W_{t+s} L_{t+s}-\frac{\psi_{L}}{1+v}\left(\frac{\bar{W}_{t}(j) \Pi_{t, t+s}^{w}}{W_{t+s}}\right)^{\frac{\lambda_{w}(1+v)}{1-\lambda_{w}}} \frac{L_{t+s}{ }^{1+v}}{\Lambda_{t+s}}\right\}
\end{aligned}
$$


Subject to a demand curve for labor (8) and the definition for constant wage which cannot reoptimize (7), the wage-setting problem's FOC with respect to $W_{t}(j)$ is;

$$
\begin{aligned}
& 0=E_{t} \sum_{s=0}^{\infty}\left(\beta \xi_{w}\right)^{s} \Lambda_{t+s} \frac{1}{1-\lambda_{w}}\left\{\left(\frac{\bar{W}_{t}(j) \prod_{t, t+s}^{w}}{W_{t+s}}\right)^{\frac{\lambda_{w}}{1-\lambda_{w w}}} L_{t+s}-\frac{\psi_{L} \lambda_{w}}{\Lambda_{t+s}}\left(\frac{\bar{W}_{t}(j) \prod_{t, t+s}^{w}}{W_{t+s}}\right)^{\frac{\lambda_{w}(1+v)}{1-\lambda_{w}-1}}\left(W_{t+s}\right)^{-1} L_{t+s}{ }^{1+v}\right\} \\
& 0=E_{t} \sum_{s=0}^{\infty}\left(\beta \xi_{w}\right)^{s} \Lambda_{t+s} \frac{L_{t+s}(j)}{1-\lambda_{w}}\left\{1-\frac{\psi_{L} \lambda_{w}}{\Lambda_{t+s}} \frac{1}{\bar{W}_{t}(j) \Pi_{t, t+s}^{w}}\left(\frac{\bar{W}_{t}(j) \Pi_{t, t+s}^{w}}{W_{t+s}}\right)^{\frac{v \lambda_{w}}{1-\lambda_{w}}} L_{t+s}{ }^{v}\right\} \\
& 0=E_{t} \sum_{s=0}^{\infty}\left(\beta \xi_{w}\right)^{s} \Lambda_{t+s} \frac{L_{t+s}(j)}{1-\lambda_{w}}\left\{\bar{W}_{t}(j) \Pi_{t, t+s}^{w}-\frac{\psi_{L} \lambda_{w}}{\Lambda_{t+s}} L_{t+s}(j)^{v}\right\} \quad, \hat{\lambda}_{t+s}=\Lambda_{t+s} P_{t+s} A_{t+s}, \quad \bar{w}=\frac{\bar{W}_{t}}{W_{t}}, \hat{w}_{t}=\frac{W_{t}}{P_{t} A_{t}} \\
& 0=E_{t} \sum_{s=0}^{\infty}\left(\beta \xi_{w}\right)^{s} \frac{\hat{\lambda}_{t+s}}{P_{t+s} A_{t+s}} \frac{L_{t+s}(j)}{1-\lambda_{w}}\left\{\bar{w}_{t} \hat{w}_{t} P_{t} A_{t} \Pi_{t, t+s}^{w}-\psi_{L} \lambda_{w} \frac{P_{t+s} A_{t+s}}{\hat{\lambda}_{t+s}} L_{t+s}(j)^{v}\right\} \\
& 0=E_{t} \sum_{s=0}^{\infty}\left(\beta \xi_{w}\right)^{s}=E_{t} \sum_{s=0}^{\infty}\left(\beta \xi_{w}\right)^{s} \hat{\lambda}_{t+s} \frac{L_{t+s}(j)}{1-\lambda_{w}}\left\{\bar{w}_{t} \hat{w}_{t} \bar{\Pi}_{t, t+s}^{w}-\psi_{L} \lambda_{w} \frac{L_{t+s}(j)^{v}}{\hat{\lambda}_{t+s}}\right\}
\end{aligned}
$$

The wage evolves according to follows, which dividing through by $W_{t-1}$ and rearranging yields the relative wage of optimizers as an increasing function of the inflation rate;

$$
\begin{aligned}
& W_{t} \frac{1}{1-\lambda_{w}}=\left(1-\xi_{w}\right) \bar{W}_{t} \frac{1}{1-\lambda_{w}}+\xi_{w}\left[\left(\pi_{t-1}\right)^{l w}(\pi)^{1-l w} W_{t-1}\right]^{\frac{1}{1-\lambda_{w}}} \\
& \left(\frac{W_{t}}{W_{t-1}}\right)^{\frac{1}{1-\lambda_{w}}}=\left(1-\xi_{w}\right)\left(\frac{W_{t}}{W_{t-1}}\right)^{\frac{1}{1-\lambda_{w}}}+\xi_{w}\left(\frac{\left(\pi_{t-1}\right)^{l w}(\pi)^{1-l w} W_{t-1}}{W_{t-1}}\right)^{\frac{1}{1-\lambda_{w}}} \\
& \left(\frac{W_{t}}{W_{t-1}}\right)^{\frac{1}{1-\lambda_{w}}}=\left(1-\xi_{w}\right)\left(\frac{\bar{w}_{t} W_{t}}{W_{t-1}}\right)^{\frac{1}{1-\lambda_{w}}}+\xi_{w}\left(\left(\pi_{t-1}\right)^{l w}(\pi)^{1-l w}\right)^{\frac{1}{1-\lambda_{w}}} \\
& \left(\frac{W_{t}}{W_{t-1}}\right)^{\frac{1}{1-\lambda_{w}}}-\xi_{w}\left(\left(\pi_{t-1}\right)^{l w}(\pi)^{1-l w}\right)^{\frac{1}{1-\lambda_{w}}}=\left(1-\xi_{w}\right)\left(\frac{\bar{w}_{t} W_{t}}{W_{t-1}}\right)^{\frac{1}{1-\lambda_{w}}} \\
& \bar{w}_{t}=\left[\frac{\left(\frac{W_{t}}{W_{t-1}}\right)^{\frac{1}{1-\lambda_{w}}}-\xi_{w}\left(\left(\pi_{t-1}\right)^{l w}(\pi)^{1-l w}\right)^{\frac{1}{1-\lambda_{w}}}}{\left(1-\xi_{w}\right)\left(\frac{W_{t}}{W_{t-1}}\right)^{\frac{1}{1-\lambda_{w}}}}=\left(\frac{1-\xi_{w}\left(\frac{w_{t-1}}{\hat{w}_{t}} \Pi_{t-1, t}^{w}\right)^{\frac{1}{1-\lambda_{w}}}}{1-\xi_{w}}\right)^{1-\lambda_{w}}\right.
\end{aligned}
$$

Subject to (23), (25), (26), (27) and substituting the capital stock (16) into the problem satisfies;

$$
\begin{aligned}
& V_{t}^{j}\left(K_{t}^{j}\right)=\max _{\left\{I_{i}^{j} \geq 0\right\}} R_{t}^{j} K_{t}^{j}-P_{t}^{I} I_{t}^{j}+\left(1-\delta_{e}\right) E_{t} \frac{\beta \Lambda_{t+1}}{\Lambda_{t}} V_{t+1}^{j}\left(K_{t+1}^{j}\right) \\
& =\max _{\left\{I_{t}^{j} \geq 0\right\}} R_{t}^{j} K_{t}^{j}-P_{t}^{I} I_{t}^{j}+\left(1-\delta_{e}\right) E_{t} \frac{\beta \Lambda_{t+1}}{\Lambda_{t}}\left(Q_{t+1}^{j} K_{t+1}^{j}+B_{t+1, \tau+1}^{j}\right) \\
& =\max _{\left\{I_{i}^{j} \geq 0\right\}} R_{t}^{j} K_{t}^{j}-P_{t}^{I} I_{t}^{j}+Q_{t} K_{t+1}^{j}+\bar{B}_{t, \tau}^{j} \\
& =\max _{\left\{I_{t}^{\prime} \geq 0\right\}} R_{t}^{j} K_{t}^{j}-P_{t}^{I} I_{t}^{j}+Q_{t}\left((1-\delta) K_{t}^{j}+\mu_{t} \varepsilon_{t}^{j} I_{t}^{j}\right)+\bar{B}_{t, \tau}^{j} \\
& =\max _{\left\{I_{i}^{\prime} \geq 0\right\}} R_{t}^{j} K_{t}^{j}+\left(Q_{t} \mu_{t} \varepsilon_{t}^{j}-P_{t}^{I}\right) I_{t}^{j}+Q_{t}(1-\delta) K_{t}^{j}+\bar{B}_{t, \tau}^{j} \\
& Q_{t}^{j} K_{t}^{j}+B_{t, \tau}^{j}=\max _{\left\{I_{t}^{\prime} \geq 0\right\}} R_{t}^{j} K_{t}^{j}+\left(Q_{t} \mu_{t} \varepsilon_{t}^{j}-P_{t}^{I}\right) I_{t}^{j}+Q_{t}(1-\delta) K_{t}^{j}+\bar{B}_{t, \tau}^{j}
\end{aligned}
$$

The (A.4)'s FOC with repect to $I_{t}^{j}$ yields the Lagrangean as;

$$
\begin{aligned}
& Q_{t} \mu_{t} \varepsilon_{t}^{j}-P_{t}^{I} \geq 0 \\
& \frac{Q_{t} \mu_{t} \varepsilon_{t}^{j}}{P_{t}^{I}}-1 \geq 0 \\
& \xi_{t}^{j}=\frac{\varepsilon_{t}^{j}}{\varepsilon_{t}^{*}}-1 \geq 0
\end{aligned}
$$

Profit maximization leads to the following first order condition: 


$$
\begin{aligned}
& \pi_{y}=P_{t} Y_{t}-\int_{0}^{1} P_{t}(i) Y_{t}(i) d i \\
& =P_{t}\left[\int_{0}^{1} Y_{t}(i)^{\frac{1}{\lambda_{p}}} d i\right]_{0}^{\lambda_{p}}-\int_{0}^{1} P_{t}(i) Y_{t}(i) d i \\
& \frac{\partial \pi_{y}}{\partial Y_{t}(i)}=P_{t}\left(Y_{t}\right)^{\frac{\lambda_{p}}{1-\lambda_{p}}} Y_{t}(i)^{\frac{1-\lambda_{p}}{\lambda_{p}}}-P_{t}(i)=0
\end{aligned}
$$

The first-order condition for the solution of the above problem implies that all firms revising their price at time $t$ will choose a common optimal price level, $\bar{P}_{t}(i)$, set according to the following log-linear rule;

$$
\begin{aligned}
& \max _{\left\{P_{t}(i)\right\}} E_{t} \sum_{s=0}^{\infty}\left(\beta \xi_{p}\right)^{s} \Lambda_{t+s}\left[P_{t+s}(i) Y_{t+s}(i)-P_{t+s}^{w} Y_{t+s}(i)\right] \\
& =\max _{\left\{P_{t}(i)\right\}} E_{t} \sum_{s=0}^{\infty}\left(\beta \xi_{p}\right)^{s} \Lambda_{t+s} Y_{t+s}\left[\left(\frac{P_{t+s}(i)}{P_{t+s}}\right)^{\frac{1}{1-\lambda_{p}}} P_{t+s}-P_{t+s}^{w}\left(\frac{P_{t+s}(i)}{P_{t+s}}\right)^{\frac{\lambda_{p}}{1-\lambda_{p}}}\right] \quad, p_{t+s}^{w}=\frac{P_{t+s}^{w}}{P_{t+s}} \\
& =\max _{\left\{P_{t}(i)\right\}} E_{t} \sum_{s=0}^{\infty}\left(\beta \xi_{p}\right)^{s} \Lambda_{t+s} Y_{t+s} P_{t+s}\left[\left(\frac{P_{t+s}(i)}{P_{t+s}}\right)^{\frac{1}{1-\lambda_{p}}}-p_{t+s}^{w}\left(\frac{P_{t+s}(i)}{P_{t+s}}\right)^{\frac{\lambda_{p}}{1-\lambda_{p}}}\right] \\
& =\max _{\left\{P_{t}(i)\right\}} E_{t} \sum_{s=0}^{\infty}\left(\beta \xi_{p}\right)^{s} \Lambda_{t+s} Y_{t+s} P_{t+s}\left[\left(\frac{\bar{P}_{t}(i) \Pi_{t, t+s}^{p}}{P_{t+s}}\right)^{\frac{1}{1-\lambda_{p}}}-p_{t+s}^{w}\left(\frac{\bar{P}_{t}(i) \Pi_{t, t+s}^{p}}{P_{t+s}}\right)^{\frac{\lambda_{p}}{1-\lambda_{p}}}\right] \quad, P_{t+s}(i)=\bar{P}_{t}(i) \Pi_{t, t+s}^{p}
\end{aligned}
$$

Subject to a demand curve for output (38) and the definition for constant price which cannot reoptimize (40), the price-setting problem's FOC with respect to $P_{t}(i)$ is;

$$
\begin{aligned}
& 0=E_{t} \sum_{s=0}^{\infty}\left(\beta \xi_{p}\right)^{s} \Lambda_{t+s} Y_{t+s} P_{t+s}\left[\frac{1}{1-\lambda_{p, t+s}} \frac{\Pi_{t, t+s}^{p}}{P_{t+s}}\left(\frac{\bar{P}_{t}(i) \Pi_{t, t+s}^{p}}{P_{t+s}}\right)^{\frac{1}{1-\lambda_{p}}-1}-\frac{\lambda_{p, t+s}}{1-\lambda_{p, t+s}} \frac{p_{t+s}^{w} \Pi_{t, t+s}^{p}}{P_{t+s}}\left(\frac{\bar{P}_{t}(i) \Pi_{t, t+s}^{p}}{P_{t+s}}\right)^{\frac{\lambda_{p}}{1-\lambda_{p}}-1}\right] \\
& 0=E_{t} \sum_{s=0}^{\infty}\left(\beta \xi_{p}\right)^{s} \Lambda_{t+s} P_{t+s} \frac{Y_{t+s}(i)}{1-\lambda_{p}}\left[\frac{\prod_{t, t+s}^{p}}{P_{t+s}}-\lambda_{p} p_{t+s}^{w} \frac{\Pi_{t, t+s}^{p}}{P_{t+s}}\left(\frac{\bar{P}_{t}(i) \Pi_{t, t+s}^{p}}{P_{t+s}}\right)^{-1}\right] \quad, \bar{p}_{t}=\frac{\bar{P}_{t}}{P_{t}}, Y_{t+s}(i)=\left(\frac{\bar{P}_{t}(i) \Pi_{t, t+s}^{p}}{P_{t+s}}\right)^{\frac{\lambda_{p}}{1-\lambda_{p}}} Y_{t+s} \\
& 0=E_{t} \sum_{s=0}^{\infty}\left(\beta \xi_{p}\right)^{s} \Lambda_{t+s} P_{t+s} \frac{Y_{t+s}(i)}{1-\lambda_{p}}\left[\bar{p}_{t} \bar{\Pi}_{t, t+s}^{p}-\lambda_{p} p_{t+s}^{w}\right] \quad, \hat{\lambda}_{t+s}=\Lambda_{t+s} P_{t+s} A_{t+s} \\
& 0=E_{t} \sum_{s=0}^{\infty}\left(\beta \xi_{p}\right)^{s} \hat{\lambda}_{t+s} \frac{Y_{t+s}(i) / A_{t+s}}{1-\lambda_{p}}\left[\bar{p}_{t} \bar{\Pi}_{t, t+s}^{p}-\lambda_{p} p_{t+s}^{w}\right] \quad, Y_{t+s}(i)=\left(\bar{p}_{t} \bar{\Pi}_{t, t+s}^{p}\right)^{\frac{\lambda_{p}}{1-\lambda_{s}}} Y_{t+s} \\
& 0=E_{t} \sum_{s=0}^{\infty}\left(\beta \xi_{p}\right)^{s} \hat{\lambda}_{t+s} \frac{1}{1-\lambda_{p}} \hat{Y}_{t+s}\left[\left(\bar{p}_{t} \bar{\Pi}_{t, t+s}^{p}\right)^{\frac{1}{1-\lambda_{p}}}-\lambda_{p} p_{t+s}^{w}\left(\bar{p}_{t} \bar{\Pi}_{t, t+s}^{p}\right)^{\frac{\lambda_{p}}{1-\lambda_{s}}}\right] \quad, \hat{Y}_{t+s}=Y_{t+s} / A_{t+s}
\end{aligned}
$$

Evaluating this integral taking into account the price set by current-period optimizers and taking into account that firms which do not reoptimize price are selected randomly, we obtain (after rearranging);

$$
\begin{aligned}
& P_{t,} \frac{1}{1-\lambda_{p}}=\left(1-\xi_{p}\right) \bar{P}_{t} \frac{1}{1-\lambda_{p}}+\xi_{p}\left[\left(\pi_{t-1}\right)^{l p}(\pi)^{1-l p} P_{t-1}\right]^{\frac{1}{1-\lambda_{p}}} \\
& \left(\frac{P_{t}}{P_{t}}\right)^{\frac{1}{1-\lambda_{p}}}=\left(1-\xi_{p}\right)\left(\frac{\bar{P}_{t}(i)}{P_{t}}\right)^{\frac{1}{1-\lambda_{p}}}+\xi_{p}\left(\frac{\left(\pi_{t-1}\right)^{l p}(\pi)^{1-l p} P_{t-1}}{P_{t}}\right)^{\frac{1}{1-\lambda_{p}}} \\
& 1=\left(1-\xi_{p}\right)\left(\bar{p}_{t}\right)^{\frac{1}{1-\lambda_{p}}}+\xi_{p}\left(\Pi_{t-1, t}^{p}\right)^{\frac{1}{1-\lambda_{p}}} \\
& \bar{p}_{t}=\left(\frac{1-\xi_{p}\left(\Pi_{t-1, t}^{p}\right)^{\frac{1}{1-\lambda_{p}}}}{1-\xi_{p}}\right)^{1-\lambda_{p}} \equiv \bar{p}\left(\pi_{t}\right)
\end{aligned}
$$

The aggregate output evolves according to, we substitute (65) into (14), using (20) and aggregating over $j$; 


$$
\begin{aligned}
\bar{Y}_{t}^{j} & =\left(K_{t}^{j}\right)^{\alpha}\left(A_{t} \bar{L}_{t}^{j}\right)^{1-\alpha} \\
& =\left(K_{t}^{j}\right)^{\alpha}\left(A_{t}\right)^{1-\alpha}\left(1+\xi_{t}^{j}\right)^{-\frac{1}{\alpha}}\left(L_{t}^{j}\right)^{1-\alpha} \\
& \left.=\left(K_{t}^{j}\right)^{\alpha}\left(A_{t}\right)^{1-\alpha}\left[\Phi\left(\varepsilon_{t}^{*}\right)+\int_{\varepsilon \geq \varepsilon_{t}^{*}}\left(\frac{\varepsilon_{t}^{*}}{\varepsilon}\right)^{\frac{1}{\alpha}} d \Phi(\varepsilon)\right]\left(L_{t}^{j}\right)^{1-\alpha}\right]\left(\left[\frac{P_{t}^{w}(1-\alpha) A_{t}^{1-\alpha}}{W_{t}\left(1+\xi_{t}^{j}\right)}\right]^{\frac{1}{\alpha}} K_{t}^{j}\right)^{1-\alpha} \\
& =\left(K_{t}^{j}\right)^{\alpha}\left(A_{t}\right)^{1-\alpha}\left[\Phi\left(\varepsilon_{t}^{*}\right)+\int_{\varepsilon \geq \varepsilon_{t}^{*}}\left(\frac{\varepsilon_{t}^{*}}{\varepsilon}\right)^{\frac{1}{\alpha}} d \Phi(\varepsilon)\right]\left(\Phi\left(\varepsilon_{t}^{*}\right)+\int_{\varepsilon \geq \varepsilon_{t}^{*}}\left(\frac{\varepsilon_{t}^{*}}{\varepsilon}\right)^{\frac{1-\alpha}{\alpha}} d \Phi(\varepsilon)\right. \\
& =\left(K_{t}^{j}\right)^{\alpha}\left(A_{t}\right)^{1-\alpha} \frac{\left.\Phi\left(\varepsilon_{t}^{*}\right)+\int_{\varepsilon \geq \varepsilon_{t}^{*}}\left(\frac{\varepsilon_{t}^{*}}{\varepsilon}\right)^{\frac{1}{\alpha}} d \Phi(\varepsilon)\right]^{1-\alpha}\left(\bar{L}_{t}^{j}\right)^{1-\alpha}}{[}
\end{aligned}
$$

\section{(cc) $\mathrm{BY}$}

This work is licensed under a Creative Commons Attribution 3.0 License. 